devenir Vol. 7, N¹3, ENERO - JUNIO 2020, PP. 77-102 - ESTUDIOSI ISSN 2312-7562 E-ISSN 2616-4949

UNIVERSIDAD NACIONAL DE INGENIERÍ, LIMA

doi: https://doi.org/10.21754/devenir.v7i13.765

\title{
VIRTUALIZANDO EL PATRIMONIO CULTURAL RUPESTRE: EL CASO DEL SECTOR “X” EN TORO MUERTO - AREQUIPA, PERÍU $\left.{ }^{\star \star}\right]$
}

\author{
VIRTUALIZING THE CULTURAL HERITAGE OF ROCK ART: THE CASE OF "SECTOR X” IN TORO MUERTO - \\ AREQUIPA, PERU
}

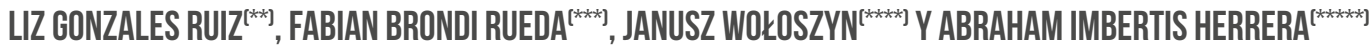 \\ (D) https://orcid.org/0000-0002-1795-6805 \\ liz.gonzales.ruiz@gmail.com \\ Investigadora independiente (Perú) \\ (iD https://orcid.org/0000-0002-1582-4892 \\ fabianbrondi@hotmail.com \\ (iD https://orcid.org/0000-0002-2320-233X \\ januszwoloszyn@uw.edu.pl \\ Universidad de Varsovia (Polonia) \\ Instituto Geográfico Nacional (Perú) \\ Dhttps://orcid.org/0000-0002-1582-4892 \\ arqueomatica.sac@gmail.com \\ Arqueomática SAC (Perú)
}

Fecha de recepción: 31 de octubre de 2019

Fecha de aprobación: 5 de febrero de 2020

\section{RESUMEN}

Toro Muerto (valle del río Majes, Arequipa-Perú), es uno de los sitios arqueológicos más grandes del mundo y con mayor cantidad de expresiones petrográficas: en un área de $10 \mathrm{~km}^{2}$ se han registrado 2.584 bloques de rocas grabadas con representaciones geométricas, zoomórficas y antropomórficas. En el 2017, al realizarse las prospecciones de acuerdo con el Proyecto de Investigación Arqueológica Toro Muerto (PIA-TM), en el extremo norte del sitio, se halló una colina con 92 petroglifos aun no estudiados (Sector X). En el 2018, se realizó un registro integral y preciso de todo el yacimiento: cada roca cuenta con fichas, fotografías calibradas, dibujos y algunos modelos 3D de rocas. Asimismo, se realizaron levantamientos geodésicos, fotogrametría del terreno, ortofotos, tecnomorfología y modelo 3D del sector y también excavaciones. El presente artículo trata sobre el estudio y la virtualización integral del patrimonio cultural rupestre del referido sector.

\section{PALABRAS CLAVE}

Sector X; Toro Muerto; Proyecto de Investigación Arqueológica Toro Muerto (PIA-TM); Virtualización; Patrimonio cultural rupestre

\section{ABSTRACT}

Toro Muerto (valley of the Majes River, Arequipa-Peru), being one of the biggest archaeological sites of Rock Art in the world, gathers an impressive amount of petrographs: within an area of $10 \mathrm{~km}^{2}$, have been registered 2584 rocks engraved with geometrical, zoomorphic and anthropomorphic representations. In 2017, during prospections for the execution of the Toro Muerto Archaeological Research Project (PIA-TM, its abbreviation in Spanish) in 2017 has been discovered a Hill with 92 petroglyphs in the extreme north of Toro Muerto, not studied yet ("Sector X"). In 2018, the sector was completely documented creating one of the most exclusive registers of the site. Each rock counts with a file, calibrated photographs, drawings and for some rocks even 3D models. Additionally geodesic data as well as photogrammetric data was collected, ortophotographs taken and 3D and tecnomorphologic models of the sector developed and some excavations realized. This article is a case study about the integral virtualization of the Rock Art Cultural Heritage of the aforementioned sector.

\section{KEYWORDS}

Sector "X"; Toro Muerto; Toro Muerto Archaeological Research Project (PIA-TM); Virtualization; Rock Art Cultural Heritage

\footnotetext{
(*) Trabajo de investigación llevado a cabo por el equipo profesional del Proyecto de Investigación Arqueológica Toro Muerto (PIA-TM)/ Toro Muerto Archaeological Research Project, en colaboración con los profesionales de la Dirección de Catastro Especial del Instituto Geográfico Nacional del Perú (IGN) y Arqueomática SAC en el marco de las intervenciones arqueológicas realizadas entre el 2017 y 2018 financiadas por el Centro Nacional de Ciencias de Polonia (beca OPUS, No 2016/23/B/HS3/01882).

(**) Licenciada en arqueología por la Universidad Nacional Federico Villarreal (UNFV) de Lima. Egresada de la Maestría en Arquitectura con mención en Gestión del Patrimonio Cultural de Centros y Sitios Históricos de la Universidad Nacional San Antonio de Abad del Cusco (UNSAAC). Directora del Proyecto de Investigación Arqueológica Toro Muerto (PIA-TM).

(***) Maestro (M.Sc) por la Universidad Tecnológica de Monterrey (México) en Manejo de Sistemas Ambientales. Especialista en geomática. Director del Área de Cartografía Especial del Instituto Geográfico Nacional (IGN).

(****) Doctor en Arqueología y catedrático del Instituto de Arqueología de la Universidad de Varsovia (UW)-Polonia. Especialista en iconografía andina, autor de libros y artículos - entre otros publicados con los Fondos Editoriales de la PUCP y del Banco de Crédito. Director científico del PIA-TM.

(****) Licenciado en arqueología por la Universidad Nacional Mayor de San Marcos (UNMSM) de Lima. Especialista en geomática aplicada a la arqueología. Gerente de la empresa Arqueomática SAC.
} 

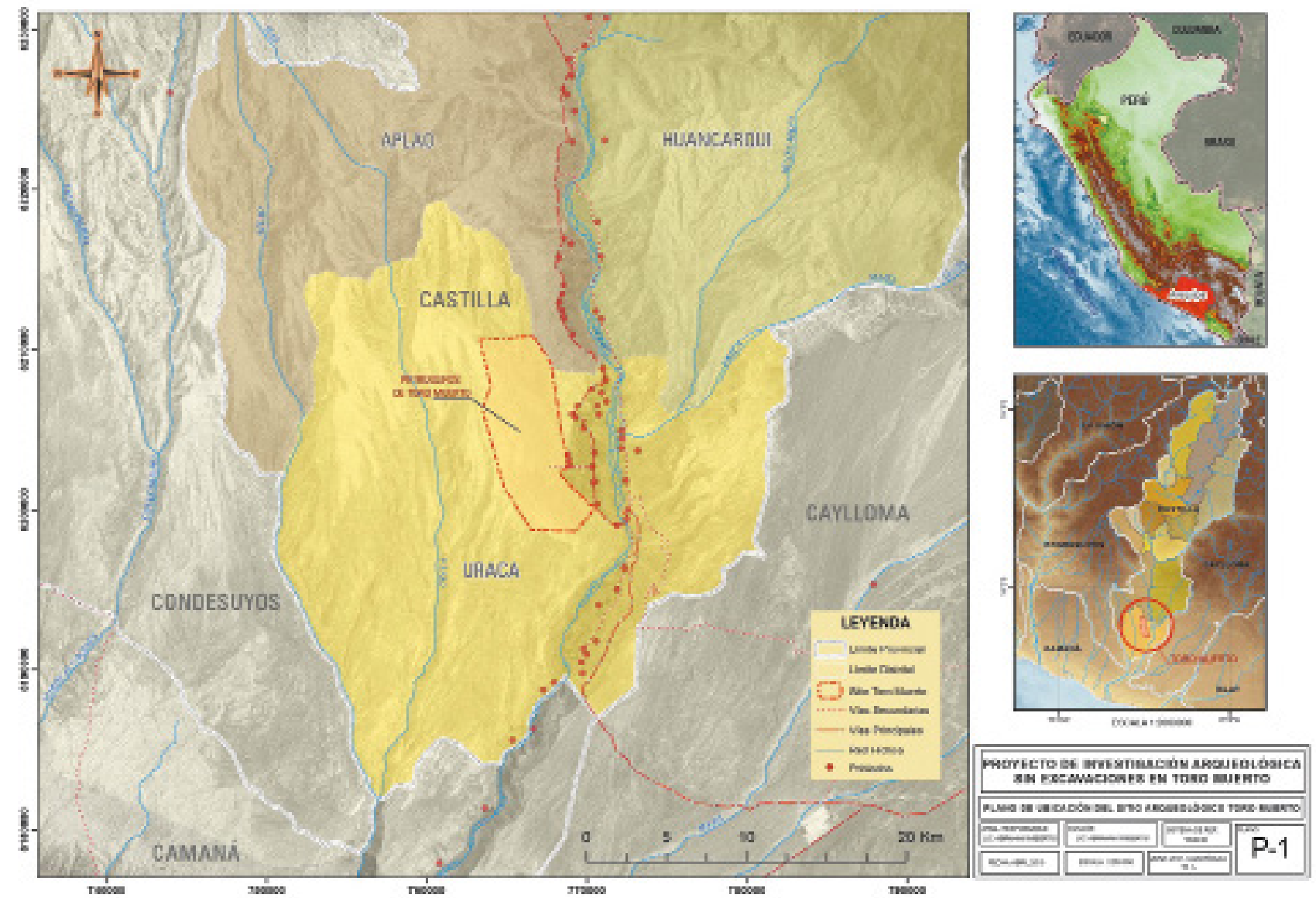

Figura 1. Plano de ubicación del sitio arqueológico Toro Muerto. Elaborado por Arqueomática SAC en base a: Carta Geográfica 18-L, Planos Topográficos del INC-1998, Coordenadas de Estación de orden B del IGN y foto satelital de Google Earth, 2017.

\section{Ubicación}

Toro Muerto está situado en la parte central del valle del río Majes en el margen izquierdo, cerca de la ciudad de Corire, Distrito de Uraca, Provincia de Castilla, Región de Arequipa, en el sur del Perú (ver Figura 1); y a 163 km de la ciudad de Arequipa, siguiendo por la Panamericana Sur (ver Figura 2). Geográficamente se halla en una pendiente inclinada, desértica y accidentada con estribaciones semi-montañosas abarcando altitudes desde los 400 a 1300 m.s.n.m.

\section{Antecedentes histórico-científicos sobre la documentación del Arte Rupestre en la región arequipeña y Toro Muerto}

Los primeros estudios científicos y técnicas de documentación de arte rupestre en la región arequipeña, se dieron alrededor del siglo XIX y fueron registrados en La Caldera (valle de Vitor) por Mariano Eduardo de Rivero y Ustariz y el suizo Johann Jakob von Tschudi' (1851), sitio también mencionado por Antonio Raymondi (1873); posteriormente, Sebastian Lorente (1891) en uno de los primeros manifiestos sobre la interpretación de los símbolos, los describió como "inscripciones"o"jeroglíficos peruanos" (Ravines, 2016, p. 157). 


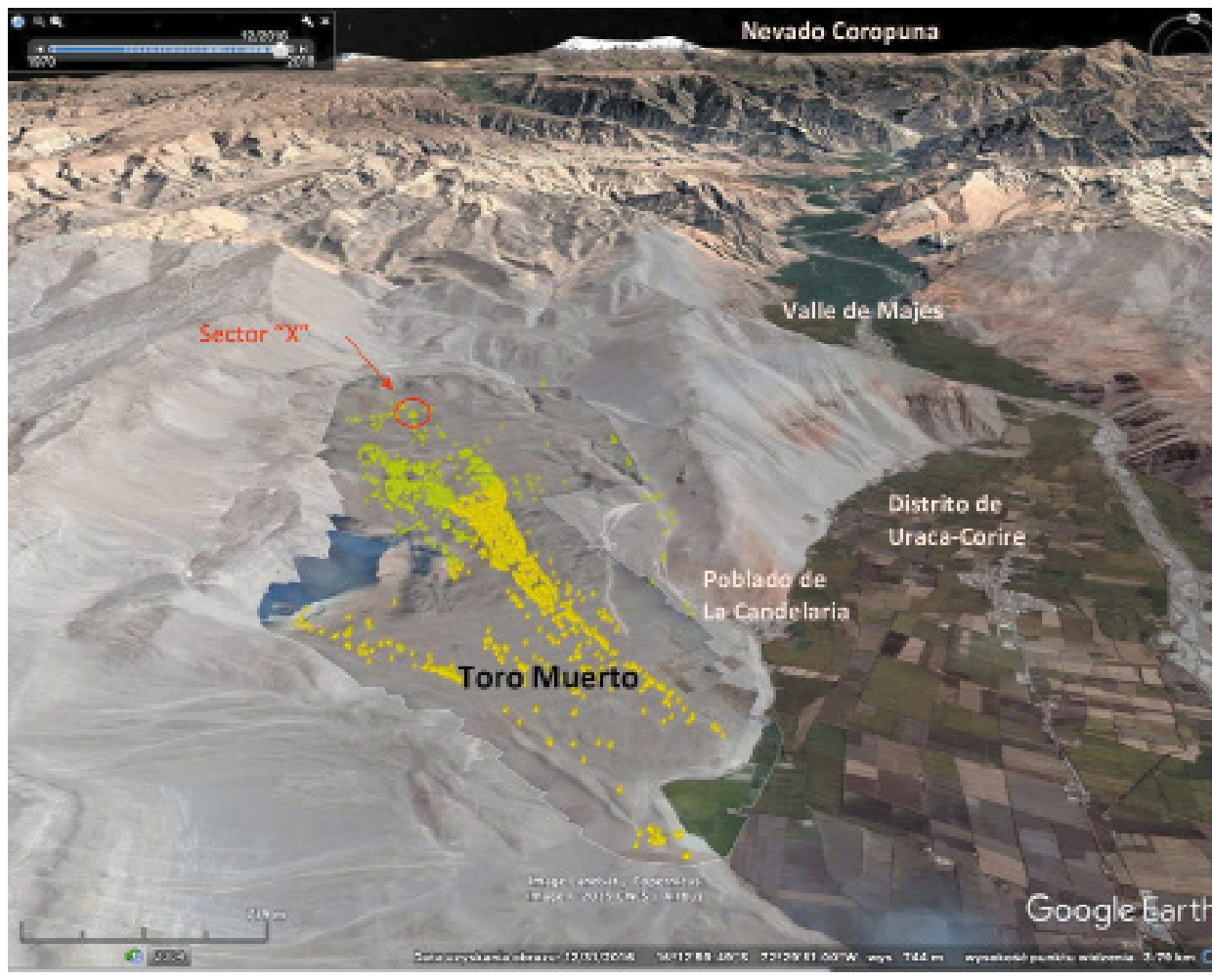

Figura 2. Inventario de $\mathbf{2 5 8 4}$ petroglifos insertados en la foto de ubicación de ubicación de Toro Muerto respecto al valle de Majes. Se indica: en verde (inventario realizado por el equipo del PIA-TM), en amarillo (inventario realizado por el equipo del PTM), en rojo (posicionamiento del Sector " $X$ " respecto al sitio). Google Earth, 2019.

En 1910, el arequipeño José Antonio Mendoza del Solar (Boletín de Lima, 2010, pp. 15-16) según parece hizo los primeros registros fotográficos en Las Calderas (Umire Álvarez, 2015), sitio al que denominaba "petroglifos", y que para esa fecha, en búsqueda de información, ya habría visitado decenas de yacimientos similares en los poblados arequipeños. Un año después, en 1910, Hiram Bingham realiza una prospección en los alrededores del nevado Coropuna (1912, pp. 489-502), e inicia así, su recorrido por algunos caminos prehispánicos (hasta ese momento en uso), cruzando por lugares donde había petroglifos como el Alto de Pitis y La Mesana (van Hoek, 2013) al lado derecho del valle de Majes y hermanados con Toro Muerto. Sin embargo, Bingham no dejó ningún tipo de documentación sobre este viaje, salvo una foto de su paso por el Alto de Pitis².

En 1936, Leónidas Bernedo Málaga anuncia otro descubrimiento sobre un repositorio de petroglifos en el pueblo de Illomas (Bernedo , pp. 4-5), estudiado y documentado posteriormente por Carlos Alberto Paz de Novoa (1940), Alfred Kroeber (1944) y José María Morante (1949) (Jennings, y otros, 2019, p. 2).

Toro Muerto fue descubierto para la ciencia por el Dr. Eloy Linares Málaga el 5 de agosto de 1951 (Linares, 2011, p. 100). Sin embargo, ya era conocido por los pobladores locales desde la primera mitad del siglo XVIII, y por desgracia fue usado como cantera para la construcción de la Hacienda Toro Grande y de la Capilla de Huarango termina-

2. Photograph Picture Id: 602411: Hiram Bingham/National Geographic Stock. 
devenir Vol. 7, N¹3, ENERO - JUNIO 2020, PP. 77-102 - ESTUDIOS | ISSN 2312-7562 I E-ISSN 2616-4949

UNIVERSIDAD NACIONAL DE INGENIERÍ, LIMA

doi: https://doi.org/10.21754/devenir.v7i13.765

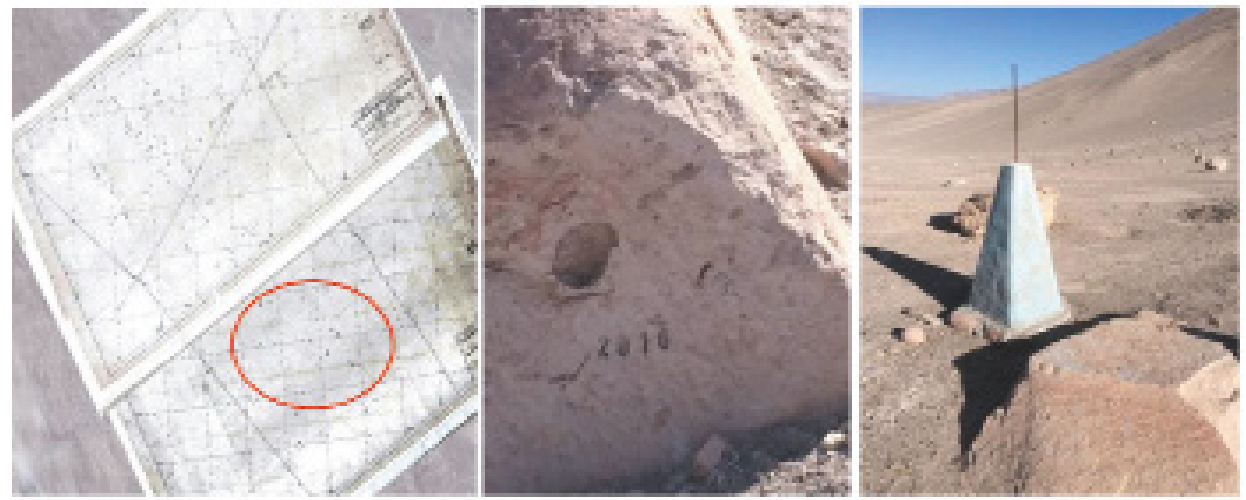

Figura 3. El primer levantamiento topográfico en 1998, incluyendo: a) plano topográfico; b) codificación numérica (inventario) de cada roca; c) hitos de demarcación del polígono del sitio arqueológico. Trabajos realizados por la delegación de arqueólogos del Instituto Nacional de Cultura-Arequipa, presidida por el Lic. Pablo De la Vera. Repositorio fotográfico del Proyecto de investigación arqueológica Toro Muerto, 2019.

da en 1722 (Linares, 2011, pág. 105) y de la cual Mariano Melgar³ habría sido Capellán en 1798 (Vargas, 2015, pp. 5,7).

Linares Málaga realiza las primeras investigaciones sobre Toro Muerto entre 1955 y 1965, sustenta su tesis doctoral en 1975 y publica también una serie de artículos y libros de carácter científico o de divulgación científica (Linares, 1970, 1973, 1990, 1999, 2005, 2012, 2014$)$

Entre 1950 y 1960, el sitio fue visitado, estudiado y documentado fotográficamente por académicos extranjeros, representantes de las misiones arqueológicas alemanas y francesas, como las de Hans Dietrich Disselhoff, Hans Horkheimer y Henry Reichlen (Linares, 2014, p. 841) (Fux, Sauerbier, Kersten, Lindstaedt, \& Eisenbeiss, 2009) (Fux, Sauerbier, Kersten, Lindstaedt, \& Eisenbeiss, 2009).

En la década de los 70 la documentación ha sido elaborada también por uno de los más conocidos investigadores del arte rupestre de esta época, el arqueólogo cubano Antonio Núñez Jiménez (1986) quien habría realizado una gran cantidad de tomas fotográficas para realizar posteriores calcos de las imágenes.

En 1998 se realizó en el área de Toro Muerto un reconocimiento con levantamiento perimétrico por parte de la sede regional del Instituto Nacional de Cultura en Arequipa (INC-A). Se marcaron entonces los límites del sitio $(50 \mathrm{~km} 2)$ y se creó el primer plano topográfico detallado del complejo, así mismo, se colocaron las nuevas codificaciones en las rocas (ver Figura 3). Para tal proyecto se utilizaron métodos de levantamiento topográfico con los instrumentos disponibles en aquella época (teodolito) y se logró inventariar una gran parte del sitio, unas dos mil rocas aproximadamente (ver Figura 4).

A principios de este siglo se desarrollaron otros tipos de intervenciones en Toro Muerto, como la de Muriel Pozzi-Escot que, en el 2000, en base al plano del INC-A, realizó la documentación de fichas y fotografías de 1151 bloques. Su método consistió en la sectorización del sitio y centró su trabajo en el Sector 6, ubicado en la parte central del complejo y en un área de 1000 × 500 metros designada arbitrariamente por Pozzi- Escot. (2009, pp. 349-361). 


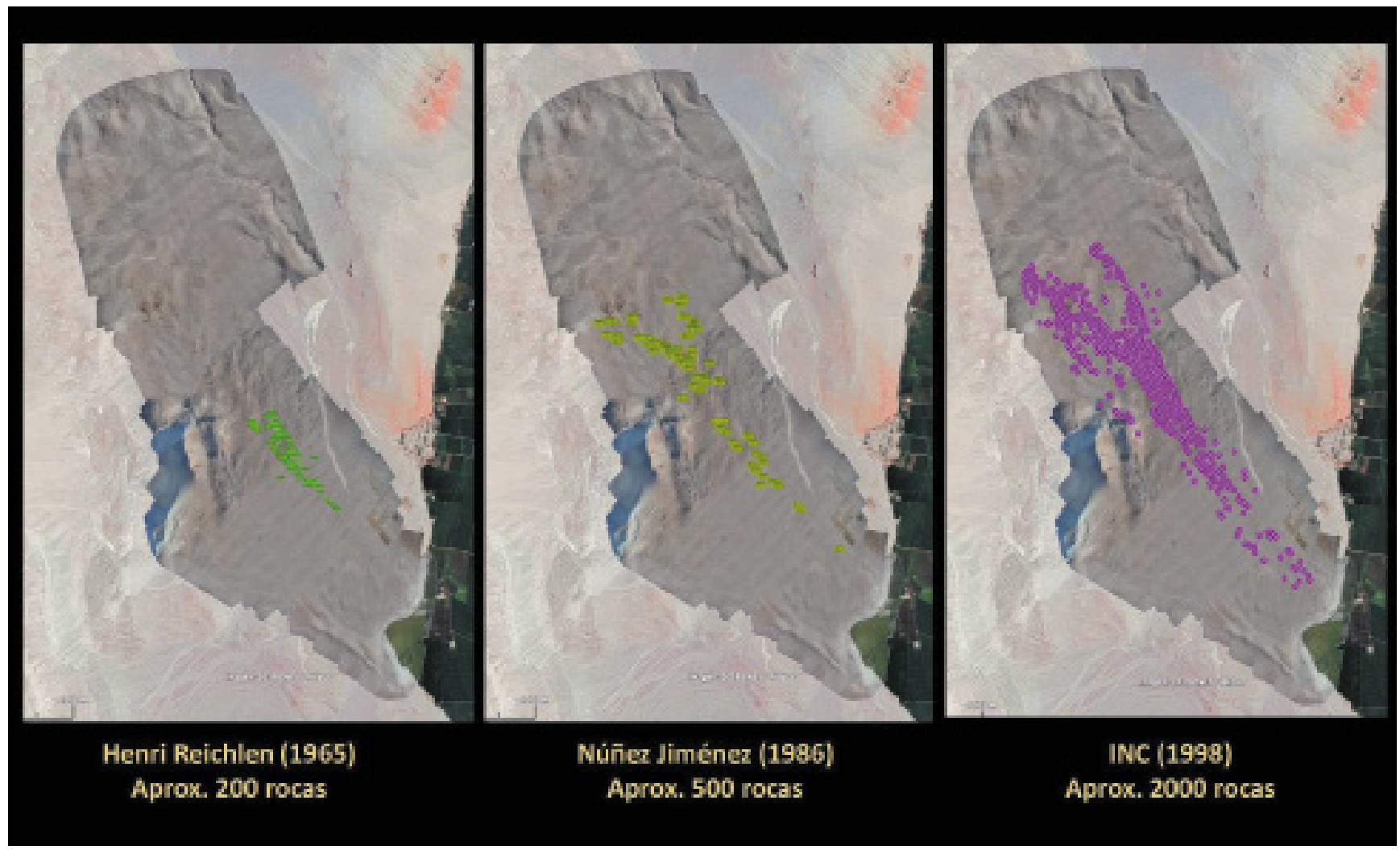

Figura 4. Vista de Toro Muerto donde se señalan las cantidades de rocas documentadas e inventariadas por los investigadores a su paso por el sitio. Google Earth, ortofoto calibrada y alta resolución insertada en Google Earth por el equipo del PIA-TM), 2019.

El 29 de enero del 2002 se inscribe a Toro Muerto en la lista del Patrimonio Cultural de la Nación por el entonces Instituto Nacional de Cultura del Perú (INC), con Resolución Directoral $\mathrm{N}^{\circ}$ 037/INC.

Daria Rosińska de la Universidad de Wrocław(Polonia) junto a Luis Héctor Rodríguez Díaz (2008) (2016), llevaron a cabo una prospección arqueológica en el perímetro del sitio y sus alrededores. Sus trabajos se enfocaron principalmente en las características del paisaje y en algunos elementos culturales propios de un sector residencial: cementerio, caminos, lugares de descanso y huellas de canales de riego.

Es necesario resaltar los trabajos realizados por Maarten van Hoek (2018) (2013) (2010) (2005) (2005) que se centraron en la interpretación de algunos motivos de la iconografía de Toro Muerto y de algunas técnicas que se usaban para su ejecución.

Finalmente, una de las últimas intervenciones fue realizada por el equipo polaco-peruano liderado por Karolina Juszczyk y Abraham Imbertis Herrera, denominado Proyecto Toro Muerto (PTM) entre los años 2015 y 2016, quienes registraron y documentaron aproximadamente unas 1600 rocas en un área de 4,02km2 (Fig. 02). Este reinventario que cubre una parte del sitio fue realizado con tecnología moderna y lo podemos ver en su página web ${ }^{4}$. 
devenir Vol. 7, N¹3, ENERO- JUNIO 2020, PP. 77-102 - ESTUDIOS | ISSN 2312-7562 | E-ISSN 2616-4949

UNIVERSIDAD NACIONAL DE INGENIERÍA, LIMA

doi: https://doi.org/10.21754/devenir.v7i13.765

\section{La virtualización del Patrimonio Cultural Rupestre, el PIA-TM y el IGN ${ }^{5}$}

Tal como lo han manifiestado Troncoso, Armstrong y Nash (2018, pp. 1-5), desde inicios del siglo XXI, los trabajos de investigación cuentan con una tecnología de punta que es producto de los avances logrados en este campo durante las dos últimas décadas: cámaras fotográficas digitales, sistemas de navegación satelital, el empleo de softwares especializados para el manejo gráfico, fotográfico y topográfico, RPA (Aeronaves Remotamente Tripuladas), LIDAR, entre otros. Todas estas herramientas, usadas en tiempo real, sirven para mejorar y acelerar los trabajos de documentación e investigación y han desplazando a las cámaras fotográficas mecánicas y al clásico papel milimetrado. Esta tecnología ha generado una revolución a nivel mundial en los proyectos arqueológicos (Criado-Boado, 2018, p. 28) (Barreda, Granado \& Aguilar, 2017, p. 2), arquitectónicos y de conservación (Quinto, 2016, p. 114). Por ende, los estudios sobre el arte rupestre también visualizan un promisor futuro gracias a estas tecnologías, ya sean para el estudio del arte o de la territorialidad (Gonzales, 2018, pp. 13-15) (Troncoso, Armstrong, \& Nash, 2018, pp. 5-8).

Por el progresivo uso y proliferación de productos de origen digital, elevados a portales web, en el 2003 la UNESCO incorpora la definición de digital heritage y se dan las Directrices para la Preservación del Patrimonio Digital y posteriormente la Carta sobre la Preservación del Patrimonio Digital'.

La Carta proclama y aprueba una serie de principios, entre ellos, el artículo 1 sobre Patrimonio Digital, para protegerlo y preservarlo por ser:

(...) los recursos que son fruto del saber o la expresión de los seres humanos, sean éstos de carácter cultural, educativo, científico o administrativo o engloben información técnica, jurídica, médica y de otras clases, se generan directamente en formato digital o se convierten a éste a partir de material analógico ya existente. Los productos "de origen digital" no existen en otro formato que no sea el electrónico original.

Entonces, bajo esta primera base, en el 2008 el Consejo Internacional de Monumentos y Sitios (ICOMOS), ratifica la Carta de Ename y su principal objetivo es "Dar a conocer los lugares patrimoniales en su más amplio contexto y en las diferentes vertientes que atañen a su significado...." En esta carta se hace mención, por primera vez, a las reconstrucciones visuales, como fuentes de información para guardar la documentación sobre el patrimonio cultural (arqueológicos, arquitectónicos e históricos) e incluso medioambientales, siempre y cuando estas sean documentadas de forma clara (Principio 2, artículo 4).

Toda esta cruzada para virtualizar el patrimonio cultural se sustenta pricipalmente en el peligro latente de desaparición o pérdida de este por diversos factores como cambio climático, desastres naturales, crecimiento urbano, conflictos armados. Es por ello que el Comité Internacional de la Photogrammétrie Architecturale (CIPA)-Heritage Documentation, asociada a ICOMOS, lidera la tendencia y las propuestas para el uso de la tecnología aplicada al registro del patrimonio.

Sin embargo, es en La Carta de Londres para la visualización computarizada del patrimonio cultural (2009) —elaborada por CIPA - Heritage Documentation en colaboración con la International Society for Photogrammetry and Remote Sensing (ISPRS) - cuando los conocedores del potencial tecnológico proponen todo aquello que engloba una correcta formulación de métodos para la virtualización del patrimonio (Quinto Fernández, 2016, pp. 115).

\footnotetext{
5. Por sus iniciales Instituto Geográfico Nacional del Perú

6. http://www.unesco.org/new/fileadmin/MULTIMEDIA/HQ/CI/CI/pdf/mow/charter_preservation_digital_heritage_es.pdf
} 
Sería demasiado extenso explicar y detallar los diferentes trabajos de virtualización del patrimonio cultural rupestre que se vienen llevando a cabo, sin embargo, hay que resaltar aquellos que sirvieron de inspiración al equipo profesional del PIA-TM. Solamente mencionaremos algunos: los de la Sociedad Escandinava del Arte Prehistórico (Scandinavian Society for Prehistoric Art - SSPA) ${ }^{7}$, el proyecto 4D VULL del Parque Cultural Valltorta-Gassulla ${ }^{8}$, el Grupo de Investigación de la Pintura Rupestre Indígena - Colombia (Grupo GIPRI) ${ }^{9}$ y CyArk $^{10}$. Este último tiene como objetivo principal la digitalización de 200 sitios patrimoniales de la arquitectura antigua e histórica amenazada a nivel mundial. Hasta el momento, en el Perú ha virtualizado Chavín (Huaraz) y Chan Chan (Trujillo).

El equipo profesional que entonces conformaba el Proyecto Toro Muerto (2015-2016) al observar su importancia y extensión propuso otro proyecto aún más complejo y ambicioso, donde se decidió abarcar $10 \mathrm{~km}^{2}$ del sitio o área donde se concentran la mayor cantidad de petroglifos para hacer uso de tecnología moderna con precisión y obtener un catálogo detallado de cada roca con sus respectivas representaciones; asimismo, se planteó una serie de excavaciones y generar el Modelo 3D del terreno, como un ortofotomapa calibrado en alto pixelaje y georreferenciado por medio de sistemas de navegación cinética satelital en tiempo real. De esta manera nace el PIA-TM, manteniendo al mismo equipo profesional del PTM en la primera etapa, empero, esta vez, dirigidas e ideadas por el Dr. Woloszyn y la Lic. Gonzales (Wołoszyn, Gonzales, \& Rozwadowski, 2019) (Juszczyk, Woloszyn, \& Rozwadowski, 2018, pp. 36-42).

Sin embargo ¿cómo obtener los resultados esperados haciendo uso de la tecnología moderna? se sabe que la tecnología se desecha rápidamente y con facilidad, por lo tanto, tiende a ser poco sostenible. Importar todos los equipos tecnológicos desde Europa a Perú es muy costoso y trasladar a los operadores de los equipos solo incrementaría el gasto y la "huella ecológica" del PIA-TM.

Hay equipos adquiridos en Polonia, como el equipo de navegación cinética satelital conocido como GPS-RTK (GNSS RUIDE R90X +NOVA R6 + control X11) y la cámara fotográfica Canon (EOS 5D Mark III Reflex de 23,4 megapíxeles) de fácil transporte. Pero ¿cómo se soluciona la adquisición de una RPA para los sobrevuelos deseados si la Dirección General de Aeronáutica Civil del Ministerio de Transporte del Perú es la única que puede otorgar los permisos para adquirirlos? Y si tenemos en cuenta que también es la única entidad que da la autorización para pilotear dichas naves, se hace aún más complicado el transporte/viaje del RPA y de su operador cuando este ingresa a territorio peruano. Ante este panorama, la única salida viable era que cada operador peruano de RPA contara con dichos permisos.

Felizmente, este problema se ha solucionado de la manera más práctica. Gracias a las teorías de consumo local, se decidió apostar por la llamada Tecnología Apropiada, un concepto bastante amigable con el medio ambiente y que apunta a descentralizar la producción de tecnología.

Se buscó dentro del mercado peruano una institución con los recursos tecnológicos apropiados y con el tipo de equipos computarizados para albergar y procesar toda la información por rescatar. De esta manera, en el 2018, se obtuvo información de que un equipo profesional del Instituto Geográfico Nacional (IGN) ${ }^{11}$ perteneciente al Ministerio de Defensa del Perú, venía realizando una serie de intervenciones (control geodésico y sobrevuelos con RPA) para la teledetección y detección remota de nuevos geoglifos en la

\footnotetext{
7. http://www.rockartscandinavia.com/

8. http://vull.4darterupestre.com/

9. http://www.gipri.net/

10. https://www.cyark.org/

11. https://www.ign.gob.pe/servicios-con-rpa/
} 
devenir Vol. 7, N¹3, ENERO- JUNIO 2020, PP. 77-102 - ESTUDIOS | ISSN 2312-7562 | E-ISSN 2616-4949

UNIVERSIDAD NACIONAL DE INGENIERÍA, LIMA

doi: https://doi.org/10.21754/devenir.v7i13.765

\begin{tabular}{ll} 
Tabla 1. Tipo de equipos tecnológicos usados en el PIA-TM \\
\hline \multicolumn{1}{c}{ Equipos } & \multicolumn{1}{c}{ Características } \\
\hline GPS RTK & GNSS RUIDE R90X +NOVA R6 + control X11 \\
RPA & Hexacóptero ABOX 6 \\
RPA & Phantom 4 DJI \\
Cámara fotográfica & Canon EOS 5D Mark III Reflex con objetivo Canon \\
& EF17-40mm f / 4L USM, de 23,4 megapíxeles \\
Ordenador & Intel ${ }^{\circledR}$ Xeon ${ }^{\circledR}$ Silver 4114 CPU @ 2.20 GHz 2.19 GHz \\
& 256 RAM \\
\hline Elaboración propia en base a la data del Proyecto de investigación arqueológica \\
Toro Muerto, 2019.
\end{tabular}

zona de Palpa-Ica, perteneciente al Proyecto Arqueológico de Palpa-Nazca y la Dirección Desconcentrada de Cultura de Ica. Además, atualmente el IGN viene realizando una serie de aportes a instituciones científicas peruanas, uno de ellos es el proyecto "Geovisor Antático Interactivo $360^{\circ}$ ", aprobado por el Ministerio de Relaciones Exteriores del Perú, donde se llevó a cabo toda la tarea geodésica para la Campaña Científica del Perú en la Antártida, conocida como ANTAR XXV.

Con toda esta información sobre el apoyo y la participación activa del IGN en las prácticas científicas del Perú, se inició una serie de conversatorios y gestiones para la cooperación científica entre los directores del PIA-TM, Dr. Janusz Z. Wołoszyn y Lic. Liz Gonzales Ruiz y el director general del IGN, General de Brigada Marco Rodríguez Monje. Dicho convenio selló la intervención del equipo profesional de la dirección de Catastro Especial ejecutado por el M. Sc. Fabián Brondi Rueda para realizar los sobrevuelos con RPA y obtener el ortofotomapa, modelo 3D del terreno y la reconstrucción digital del sitio arqueológico y del Sector " $X$ ".

De esta manera, haciendo uso de una RPA Hexacóptero ABOX 6, fabricada a medida por la empresa peruana Robotic Air Systems ${ }^{12}$ para el IGN, se logró el levantamiento de 1200 hectáreas con resolución no mayor de $5 \mathrm{~cm}$ por pixel. Los vuelos se realizaron por sobre 30 metros de altitud, con vientos a veces mayores a $40 \mathrm{~km} / \mathrm{hora}$ y cambios de suelo con pendientes irregulares y muros de cerros naturales, la nave logró sobrellevar todos los obstáculos. Así mismo, con técnicas fotométricas automatizadas, acompañadas de la geodesia (puntos tomados por el equipo profesional de Arqueomática ${ }^{13}$ ) con GPS-RTK permitieron generar información en tres dimensiones (ver Tabla 1).

\section{El Sector "X"}

Geográficamente Sector "X"14 (ver Figura 5) se emplaza en la parte superior del sitio, a 1300 m.s.n.m. aproximadamente, en el cual se eleva una colina que concentra 92 petroglifos agrupados, desde el № 2470 al № 2561 (Gonzales, 2018, pp. 37-40), todas ellas con representaciones talladas. El valor agregado que presenta este sector radica en el hecho de no haber sido intervenido por ningunos de los investigadores antes mencionados, por lo tanto, no ha sido manipulado haciendo uso de tizas, pinturas al óleo, u otro tipo de trazos, a diferencia de lo que se observa en la zona central del sitio.

\footnotetext{
12. http://www.roboticairsystems.com/

13. Dirigidos por el Lic. Abraham Imbertis.

14. Datos presentados en el Informe Final ante el Ministerio de Cultura del Perú.
} 


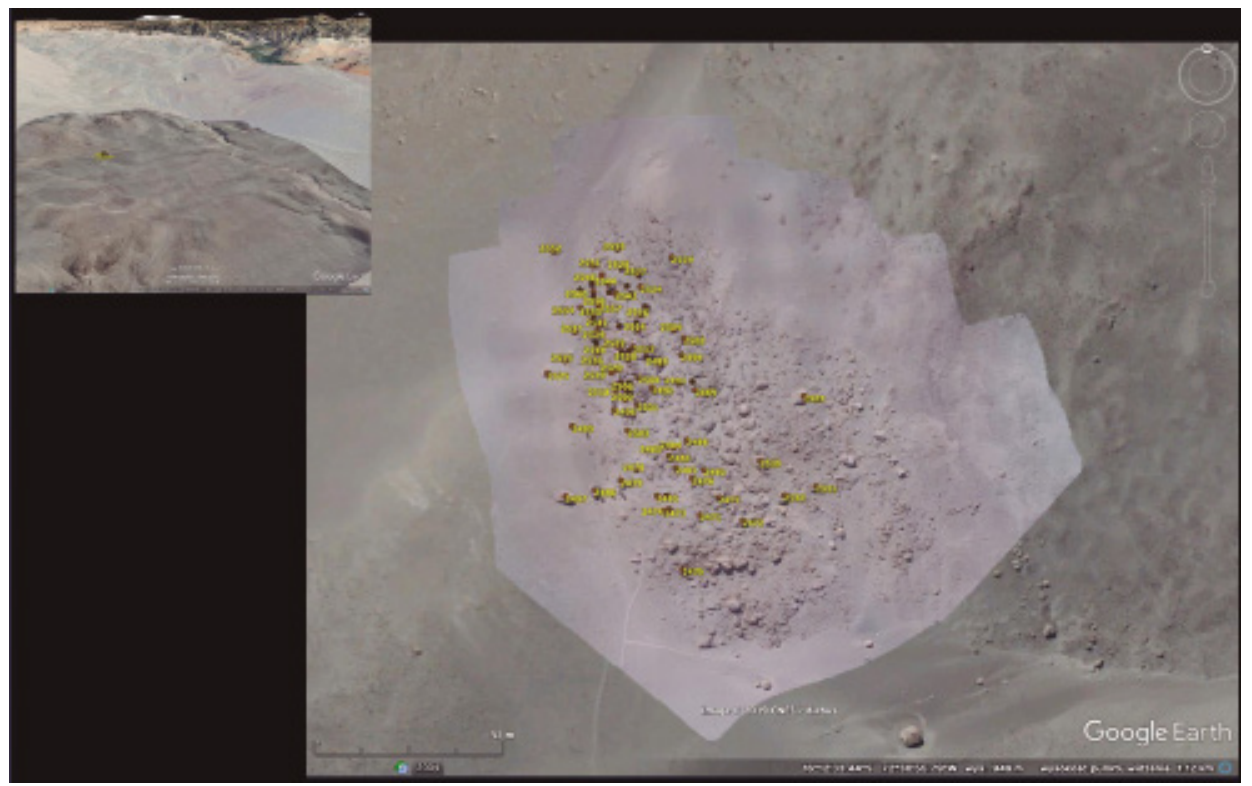

Figura 5. Foto superior: Ubicación del Sector " $X$ " al norte del sitio. Foto principal: Vista de Detalle del Sector "X" con ortofoto realizada por el IGN. Repositorio fotográfico del Proyecto de investigación arqueológica Toro Muerto, 2019.

Posteriormente a la documentación básica (inventario, ficha descriptiva, fotografías) se pudo determinar que las imágenes que presenta dicho sector no muestran las clásicas imágenes que en su mayoría se hallan en Toro Muerto, como, por ejemplo, el danzante. Si bien el Sector "X" es atractivo para una investigación integral y minuciosa es necesario en el futuro recurrir a métodos de registro fiables que aporten al entendimiento y análisis de este sector.

\section{Propuesta metodológica aplicada para la documentación del Sector "X"}

El sitio de Toro Muerto despierta constantemente interés en un grupo de investigadores, sin embargo, hasta la fecha, a pesar de los recursos tecnológicos sofisticados y/o comerciales que hoy en día se manejan para registrar sitios arqueológicos con estas características, no se observa gran avance, hay un vacío en los estudios y registros implementados por este tipo de intervenciones para el estudio del patrimonio cultural rupestre en Perú.

Para lograr un trabajo metodológico eficiente se dividió el proceso en dos etapas (ver Tabla 2). En toda la primera etapa se asumió el registro y documentación técnica del sitio arqueológico, incluyendo el Sector " $X$ ", y la segunda etapa centró su principal labor en la virtualización del referido sector, punto sobre el cual se ampliará posteriormente.

\section{1era Etapa}

Comprendió la Temporada 2017, lo que cubrió la continuación de la documentación y el proceso de calcos de paneles tallados.

\section{Documentación}

Todo lo que comprende la documentación desde la partida de nacimiento de cada roca (ver Figura 6), por lo tanto, cada una de ellas cuenta con:

1. Numeración de Inventario

2. Fichajes (descripción de cada roca y sus paneles) 
devenir Vol. 7, N¹3, ENERO- JUNIO 2020, PP. 77-102 - ESTUDIOS | ISSN 2312-7562 | E-ISSN 2616-4949

UNIVERSIDAD NACIONAL DE INGENIERÍA, LIMA

doi: https://doi.org/10.21754/devenir.v7i13.765

Tabla 2. Plan de trabajo y objetivos realizados por el PIA-TM, Temporadas 2017 y 2018.

\begin{tabular}{|c|c|c|c|c|c|}
\hline \multicolumn{2}{|c|}{$\begin{array}{c}1 \text { era Etapa } \\
\text { Temporada } 2017 \\
\text { (En relación a todo el } \\
\text { sitio arqueológico) }\end{array}$} & \multicolumn{4}{|c|}{$\begin{array}{c}\text { 2da Etapa } \\
\text { Temporada } 2018 \\
\text { (En relación con el Sec- } \\
\text { tor "X") }\end{array}$} \\
\hline \multirow[t]{5}{*}{1} & Documentación & & 1 & $\begin{array}{l}\text { Preparación de la } \\
\text { Malla Geodésica }\end{array}$ & \multirow{5}{*}{$\begin{array}{l}\text { - Posicionamiento } \\
\text { de } 1 \text { punto en el } \\
\text { Sector "X" para ama- } \\
\text { rrar este a la malla } \\
\text { geodésica. }\end{array}$} \\
\hline & $\begin{array}{l}\text { - Numeración de } \\
\text { Inventario }\end{array}$ & - del n 1 al n²584 & & $\begin{array}{l}\text { (Realizado por } \\
\text { Arqueomática) }\end{array}$ & \\
\hline & $\begin{array}{l}\text { - Fichajes (descrip- } \\
\text { ción de cada roca y } \\
\text { sus paneles) }\end{array}$ & - se cumplió con todas & & & \\
\hline & - Base Fotográfica & & & & \\
\hline & - Georreferenciación & $\begin{array}{l}\text { - Se cumplió con } \\
\text { todas } \\
\text { - Se cumplió con } \\
\text { todas }\end{array}$ & & & \\
\hline \multirow[t]{7}{*}{2} & Calcos de Paneles & \multirow{7}{*}{$\begin{array}{l}100 \text { rocas calcadas } \\
\text { entre las dos técnicas }\end{array}$} & 2 & Modelos 3D & \multirow{2}{*}{$\begin{array}{l}-50 \text { rocas a las cuales } \\
\text { se les ha realizado } \\
\text { modelaje } 3 D .20 \text { en } \\
\text { el Sector " } X \text { ", y } 30 \text { ro- } \\
\text { cas dentro del sitio } \\
\text { arqueológico. }\end{array}$} \\
\hline & \multirow[t]{6}{*}{$\begin{array}{l}\text { - Calcos tradicio- } \\
\text { nales } \\
\text { - Calcos sobre foto- } \\
\text { grafía digital }\end{array}$} & & & $\begin{array}{l}\text { (Realizado por } \\
\text { Arqueomática y } \\
\text { equipo PIA-TM) }\end{array}$ & \\
\hline & & & \multirow[t]{2}{*}{3} & Sobrevuelos con RPA & - Ortofoto, \\
\hline & & & & $\begin{array}{l}\text { (Realizado por el } \\
\text { IGN) }\end{array}$ & $\begin{array}{l}\text { - Modelos Digitales } \\
\text { de Elevación, } \\
\text { - Modelos en tres di- } \\
\text { mensiones, y } \\
\text { - Mapa temático es- } \\
\text { cala 1:1000 }\end{array}$ \\
\hline & & & 4 & $\begin{array}{l}\text { Excavaciones } \\
\text { (Realizado por el } \\
\text { equipo del PIA-TM) }\end{array}$ & 1 roca: $\mathrm{n}^{\circ} 2487$ \\
\hline & & & \multirow[t]{2}{*}{5} & Calcos de Paneles & \\
\hline & & & & $\begin{array}{l}\text { - Calcos tradicionales } \\
\text { - Calcos sobre foto- } \\
\text { grafía digital } \\
\text { (Realizado por el equi- } \\
\text { po del PIA-TM) }\end{array}$ & $\begin{array}{l}200 \text { rocas calcadas } \\
\text { entre las dos técni- } \\
\text { cas }\end{array}$ \\
\hline
\end{tabular}

Elaboración propia en base a la data del Proyecto de investigación arqueológica Toro Muerto, 2019.

\section{Base fotográfica}

\section{Georreferenciación de las rocas con petroglifos}

El registro se realizó en grupo de tres, de esta manera se generó un efecto sistemático: mientras un personal del equipo realizaba el fichaje, otro asumía la responsabilidad 


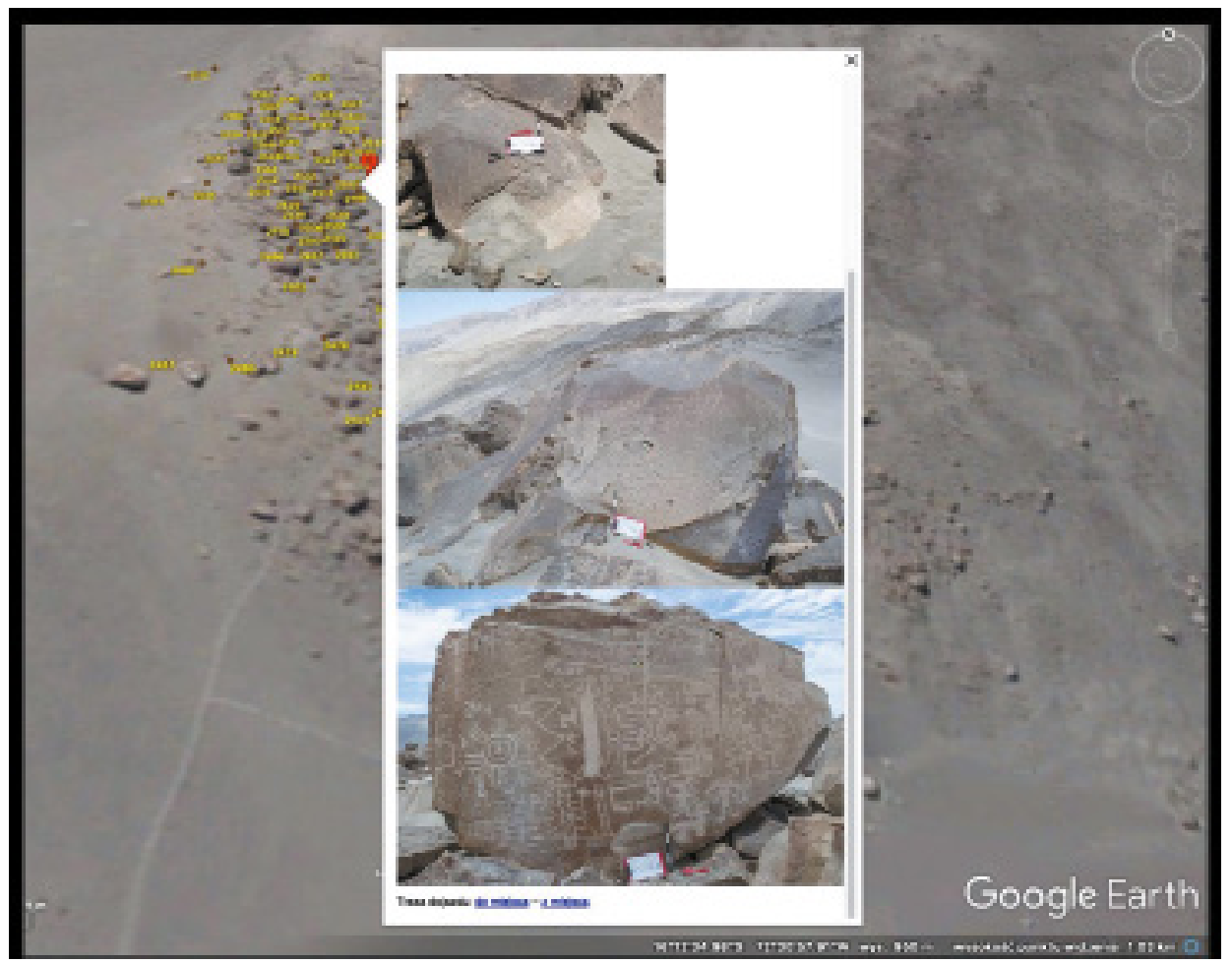

Figura 6. Foto recogida del Google Earth con el manejo de inventario, georeferenciación y documentación fotográfica del Sector "X" realizado por el Dr. Wołoszyn y el equipo del PIA-TM. Repositorio fotográfico del Proyecto de investigación arqueológica Toro Muerto, 2019.

del registro fotográfico y el especialista en geodesia proporcionaba los puntos con el GPS-RTK a cada roca.

La numeración del inventario era correlativa según el avance en la prospección y hallazgo de los petroglifos. Las fichas son una composición de diferentes observaciones como: grado de conservación, cantidad de paneles tallados, tipo de imágenes, clasificación según la escena, entre otros. La base fotográfica se realizó con la cámara del proyecto, todas las tomas presentan escalas y norte, y en las fotos de detalle se hace uso de la escala de color propuesta por el International Federation of Rock Art Organisations (IFRAO) ${ }^{15}$ (Bednarik, 1991, pp. 78).

\section{Calcos de paneles}

El calco es una herramienta clave para sistematizar el futuro del análisis iconográfico. De esta manera, se vienen realizando dos tipos metodológicos de calcos: calco tradicional y calco sobre fotografía digital.

\section{Calco tradicional}

Este método es realizado colocando paneles de polietileno transparente en la superficie de la roca tallada, adheridas con cintas adhesivas tipo masking tape. Cuatro etapas cubren este método:1) Limpieza de la superficie del petroglifo, realizado con brochas de cerda suave para levantar la acumulación arenosa. 2) Colocación del panel de polietileno y su respectivo rótulo. 3) Proceso del calco haciendo uso de tres diferentes 
devenir Vol. 7, N¹3, ENERO - JUNIO 2020, PP. 77-102 - EstudIOS | ISSN 2312-7562 | E-ISSN 2616-4949

UNIVERSIDAD NACIONAL DE INGENIERÍ, LIMA

doi: https://doi.org/10.21754/devenir.v7i13.765

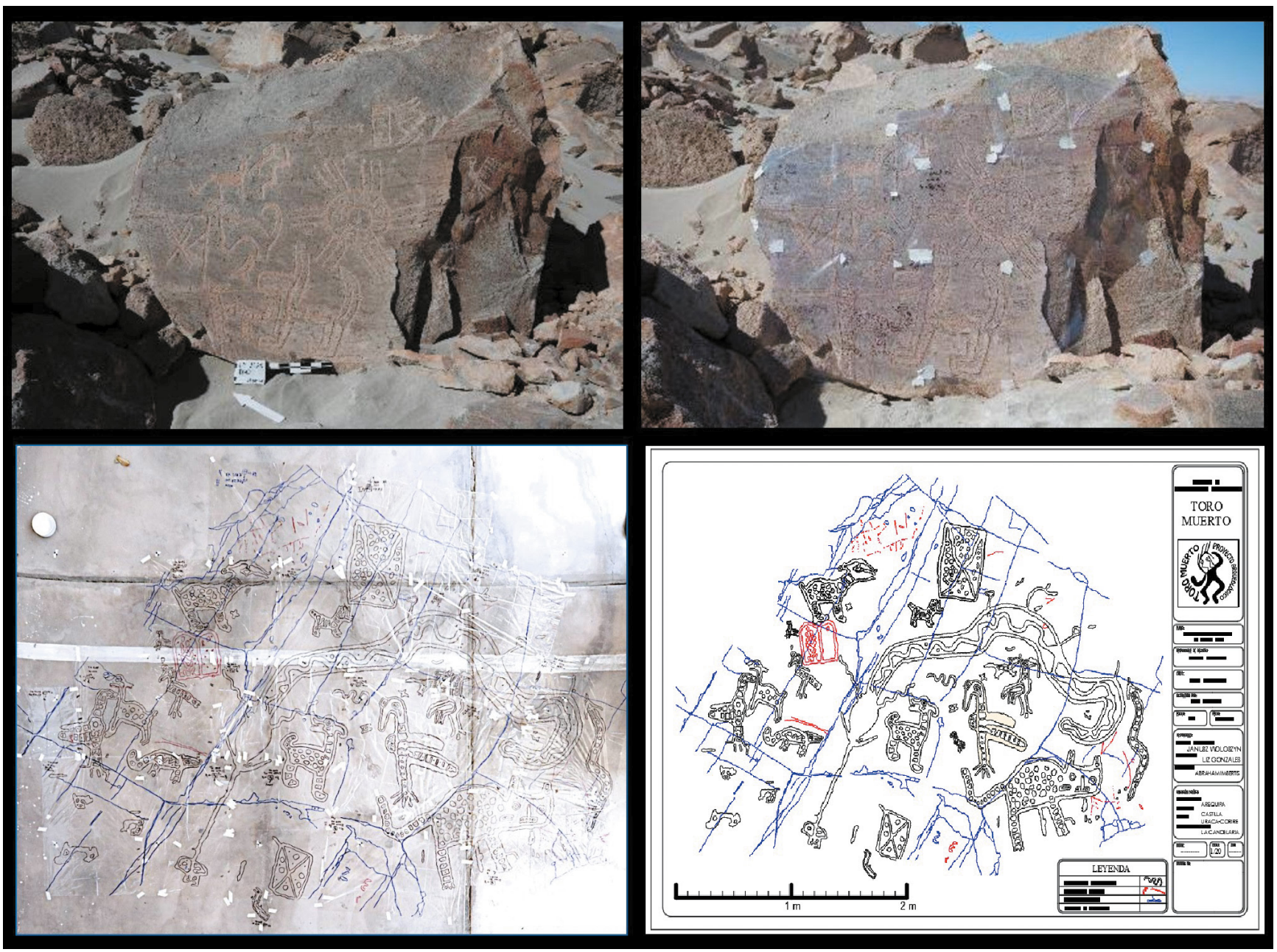

Figura 7. Método de calco tradicional: 1) limpieza. 2-3) colocación del polietileno y calco utilizando marcador indeleble: negro (imagen tallada); azul (naturaleza propia de la roca); rojo (destrucción antrópica). 3-4) reconstrucción en gabinete de los mosaicos en una superficie plana, calibrada y mallada cada $50 \mathrm{~cm}$. para obtener una ortofoto procesable en AutoCad. Repositorio fotográfico del Proyecto de investigación arqueológica Toro Muerto, 2019.

colores de marcador indeleble; negro, para reconocer la imagen tallada; azul, para reconocer todo aquello que pertenezca a la naturaleza propia de la roca (ranuras, grietas y bordes); y rojo para reconocer la destrucción antrópica o vandalismo. Y, finalmente: 4) En el gabinete se reconstruyen los mosaicos o paneles calcados en una superficie plana o piso debidamente calibrado y mallado cada $50 \mathrm{~cm}$ con la finalidad de obtener una ortofoto del mosaico con cámara de alta definición, que posteriormente es procesada haciendo uso de softwares especializados en diseño por computadora, como AutoCad, obteniendo un excelente y preciso producto (ver Figura 7).

Cabe resaltar que este método no altera ni daña la superficie de las rocas, por lo contrario se intenta, en la mayor medida, que las caras talladas no tengan ningún roce con las cintas adhesivas que se usan para fijar el polietileno. Cada roca seleccionada es calcada sin sobrepasar un día laborable. Además, no se propone este método clásico para sitios con pintura rupestre, la propuesta se hace únicamente para petroglifos (imágenes talladas) como los que presenta Toro Muerto. 


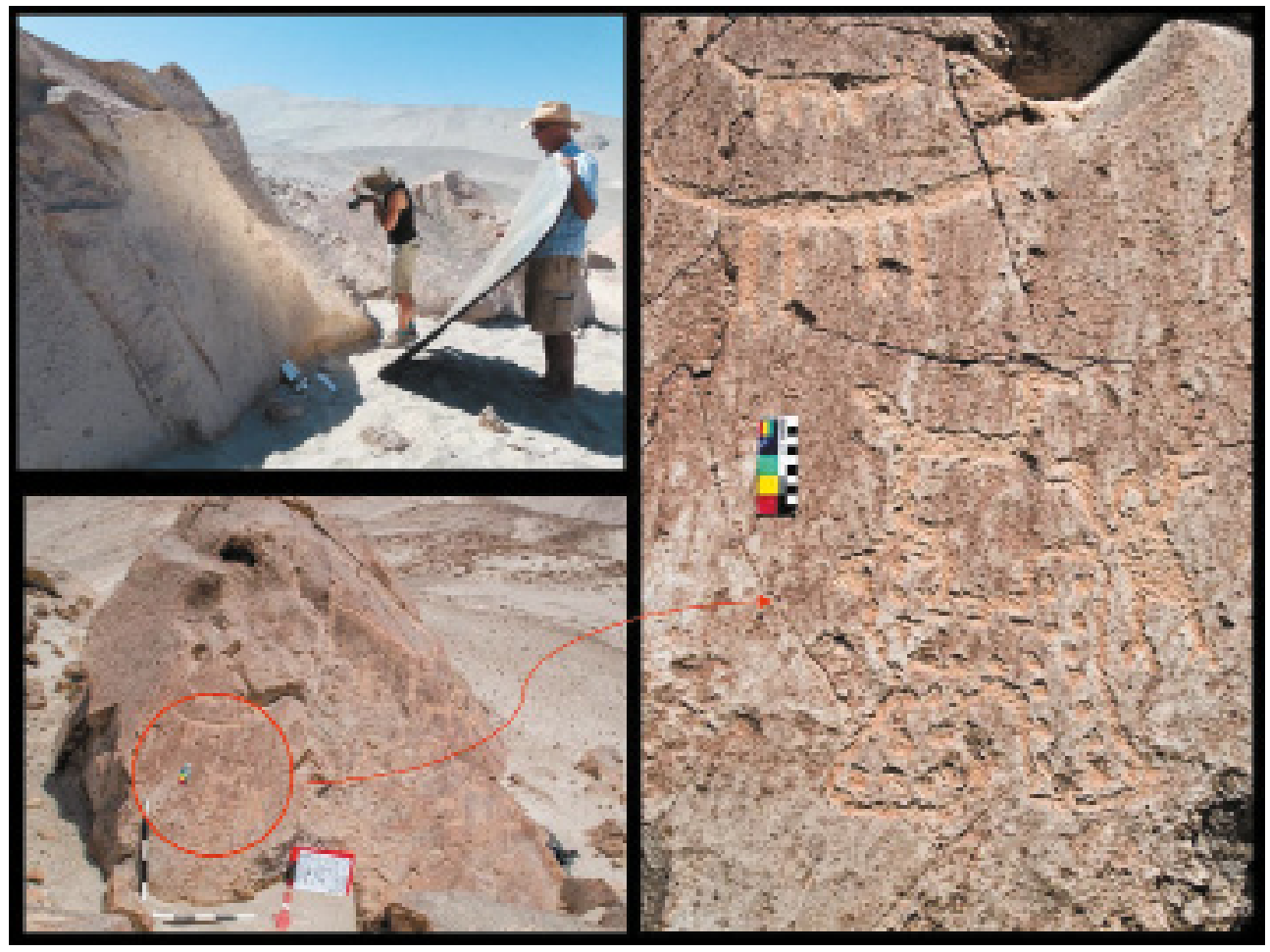

Figura 8. Proceso de tomas fotográficas digitales con apoyo de paneles para la obtención de imágenes que serán procesadas por Calco sobre fotografía digital en AutoCAD. Repositorio fotográfico del Proyecto de investigación arqueológica Toro Muerto, 2019.

Tabla 3. Tipos de software para ordenadores usados en el PIA-TM

\section{Softwares}

ArcGIS

Google Earth

AutoCAD

D-Stretch

Agisoft PhotoScan

Mission Planner

Ardupilot

Pix4d

\section{Tipo de uso}

Sistema de Información Geográfica (profesional).

Sistema de Información Geográfica (comercial) y base fotográfica.

Para georreferenciación, diseño/dibujo 2D y modelado 3D.

imagen multiespectral producto de algoritmos de descorrelación.

Para la construcción de modelos 3D. Captura de imágenes térmicas o multiespectrales.

crear planes de vuelo, organizadas en polígonos.

misiones de vuelo, respetando el perfil de elevación.

procesar un conjunto de fotos y calibrarlas por medio de algoritmos de visión computarizadas.

Elaboración propia en base a la data del Proyecto de investigación arqueológica Toro Muerto, 2019 
devenir Vol. 7, N¹3, ENERO - JUNIO 2020, PP. 77-102 - EstudIOS | ISSN 2312-7562 | E-ISSN 2616-4949

UNIVERSIDAD NACIONAL DE INGENIERÍ, LIMA

doi: https://doi.org/10.21754/devenir.v7i13.765

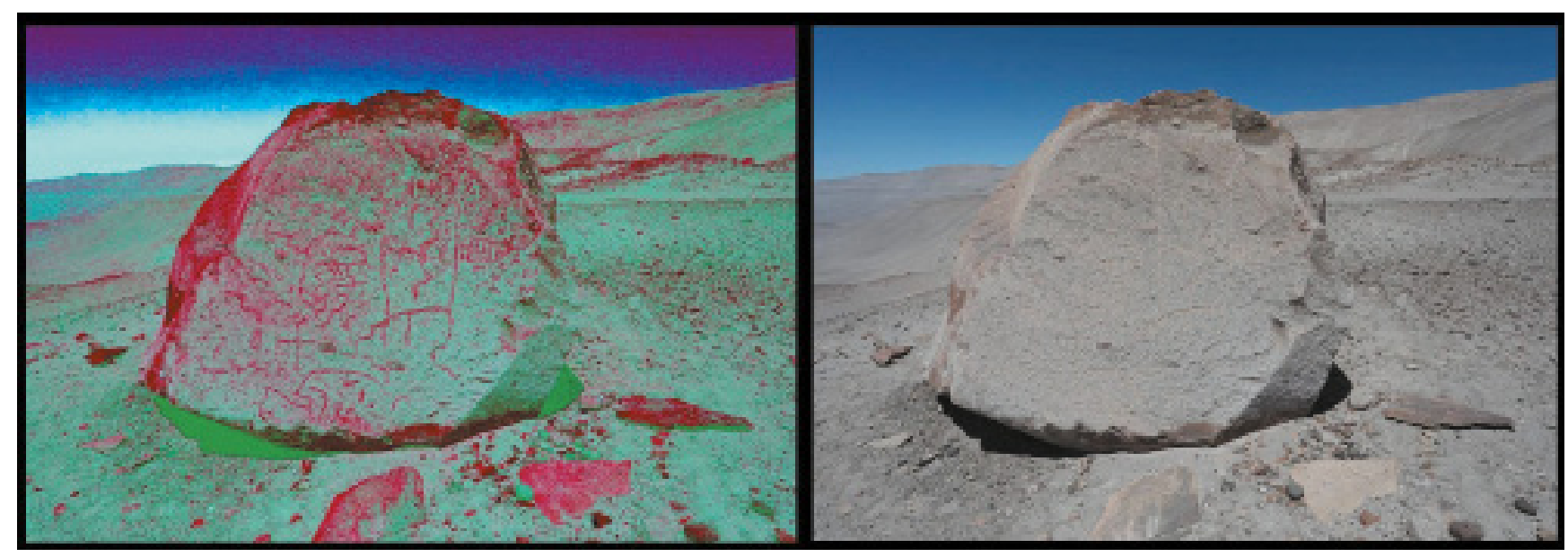

Figura 9. Tratamiento de una fotografía digital por el programa Dstrecth para el reconocimiento de imágenes difícilmente visibles. Elaboración de Rainer Hostnig sobre la base del repositorio fotográfico del Proyecto de investigación arqueológica Toro Muerto, 2019.

\section{Calco sobre fotografía digital}

Este método, versátil y económico, trata de obtener las representaciones iconográficas haciendo uso de cámaras digitales y tratadas por medio de programas (softwares) como AutoCad o DStretch, lo cual hace que estás técnicas sean menos invasivas (ver Figura 8). Seoane-Veiga et al nos manifiestan respecto a este método que "por un lado (...) el calco electrónico permite analizar la información de una manera más fiable y objetivable, y procesar datos que a simple vista son difíciles de captar" (2009, pp. 142). Claramente, se debe tener en cuenta los horarios para la obtención del producto, ya que en el caso de Toro Muerto, es difícil definir los horarios claves deben ser por la mañana o por la tarde, ya que muchas veces por el imprevisible posicionamiento de la luz natural se pueden captar imágenes solo observables por pocos minutos. Cada roca tiene una historia propia, por lo tanto, cada panel. Para mantener un ritmo preciso de trabajo, el equipo cuenta con el apoyo de paneles de luz para las tomas fotográficas.

Una vez tomada la foto digital obtenida con escala y paleta de colores propuesta por el IFRAO, dicha imagen es procesada (calcada) en AutoCad, y en algunos casos tratada por medio del programa DStretch ${ }^{16}$ (ver Tabla 3).

Este programa que pertenece al sofware Image-J y ha sido creado por el ingeniero Dr. Jon Harman para su uso exclusivo en arte rupestre, puede mostrar pictografías y petroglifos casi invisibles, donde las fotos pueden ser obtenidas sin filtros especiales, ni iluminación y dan como resultado una imagen multiespectral producto de algoritmos de descorrelación (Quesada, 2008, pp. 11-13). Una vez procesadas las imágenes por medio de este software se puede realizar el calco electrónico deseado (ver Figura 9).

\section{2da Etapa: Virtualizando el Patrimonio Cultural Rupestre del Sector "X"}

Esta fase se llevó a cabo en la Temporada 2018, año en el que se contó con la participación del ING y de la empresa Arqueomática SAC, para definir los siguientes objetivos: Preparación de la malla geodésica, Sobrevuelos con RPA y Modelos 3D (de rocas y fragmentos de terreno). 


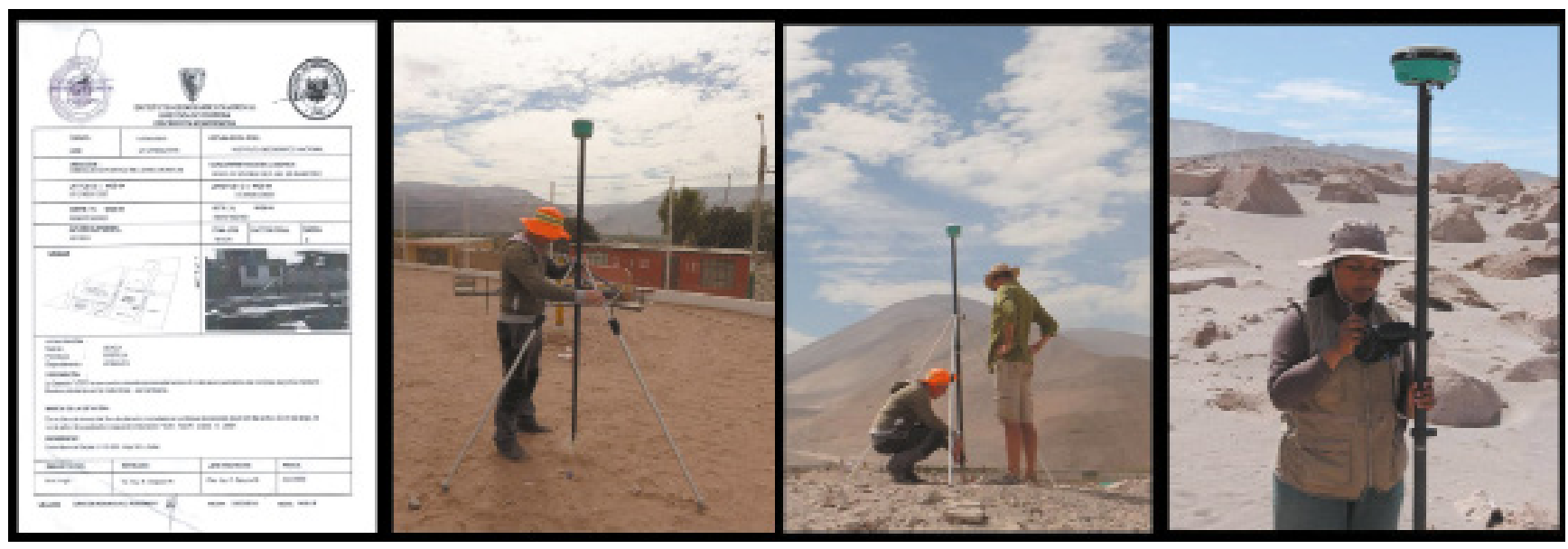

Figura 10. Imágenes con el proceso de obtención del Punto de Orden "C". Repositorio fotográfico del Proyecto de investigación arqueológica Toro Muerto, 2019.

\section{Preparación de la malla geodésica}

Esta tarea le correspondió al equipo de Arqueomática SAC, y para lograr obtener la malla se adquirió previamente el documento oficial con los datos del Punto de Orden " $C$ " correspondiente al IGN, el cual se ubica en la loza deportiva del poblado de La Candelaria (ver Figura10). De esta manera se instaló el GPS-RTK en dicho punto por más de 6 horas para recibir la frecuencia satelital del posicionamiento sin márgenes de error y a tiempo real. Una vez rastreado y fijado el punto de Orden " $C$ " se pudo transportar una serie de estos para generar la malla, enlazando, especialmente, siete puntos geodésicos como los principales. Al utilizar programas de sistemas de información geográficas como el ArcGIS, AutoCAD y Google Earth se dio paso a la construcción de la georreferenciación del terreno.

\section{Modelos 3D (de rocas con petroglifos)}

Una actividad que generó la creación del PIA-TM, fueron las técnicas y tendencias para las reconstrucciones en 3D de las rocas grabadas. Fue interesante ver los resultados obtenidos por el equipo del PTM, visibles en la página web de dicho proyecto: www. toro-muerto.com.

En los últimos años estas técnicas han ido evolucionando y, aprovechando todo su potencial, se han convertido en una herramienta indispensable en el registro del patrimonio cultural rupestre a nivel mundial.

La fotogrametría 3D se convierte en una herramienta rápida, económica y flexible con la que se puede cubrir una gran cantidad de tomas en un solo día. Se debe resaltar que el producto final lo determina el tipo de cámara y el software que se use para reconstruir el modelo.

Para el trabajo realizado en el PIA-TM se usó la cámara profesional Canon EOS 5D Mark III Reflex con objetivo Canon EF17-40mm f / 4L USM, de 23,4 megapíxeles. Por cada roca con petrograbados seleccionado se tomó un aproximado de 100 a 150 disparos fotográficos rodeando toda la roca, además de una serie de fotos de los detalles en varios ángulos. Dependiendo de la complejidad de los diseños, las tomas tienen un acercamiento de entre $30 \mathrm{~cm}$ a $100 \mathrm{~cm}$. Además, para este tipo de trabajo no se usaron reglas o escalas, sólo pequeños puntos fijos (tipo escalas de $2 \times 2 \mathrm{~cm}$ ) en la superficie de las caras con imágenes lo que ayudó a generar una nube de puntos. Dichos puntos fueron registrados con el GPS RTK lo que formó 
devenir Vol. 7, N¹3, ENERO - JUNIO 2020, PP. 77-102 - ESTUDIOS | ISSN 2312-7562 | E-ISSN 2616-4949

UNIVERSIDAD NACIONAL DE INGENIERÍA, LIMA

doi: https://doi.org/10.21754/devenir.v7i13.765

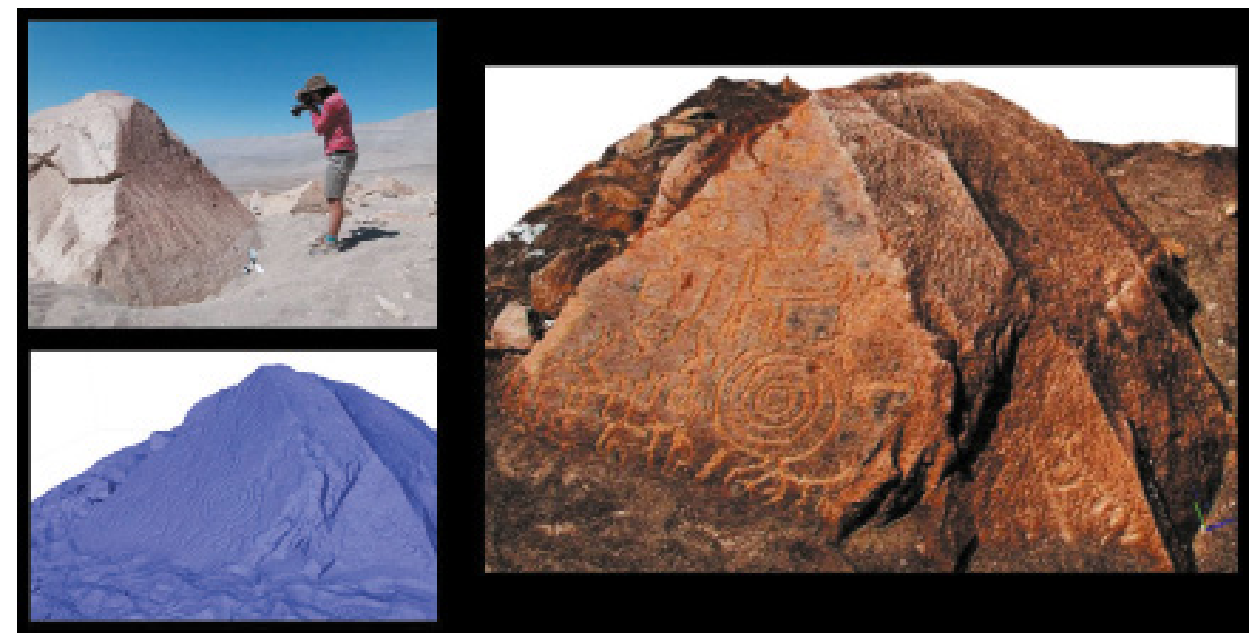

Figura 11. Proceso del Modelo 3D de las rocas con petroglifos haciendo uso del programa Agisoft PhotoScan. Repositorio fotográfico del Proyecto de investigación arqueológica Toro Muerto, 2019.

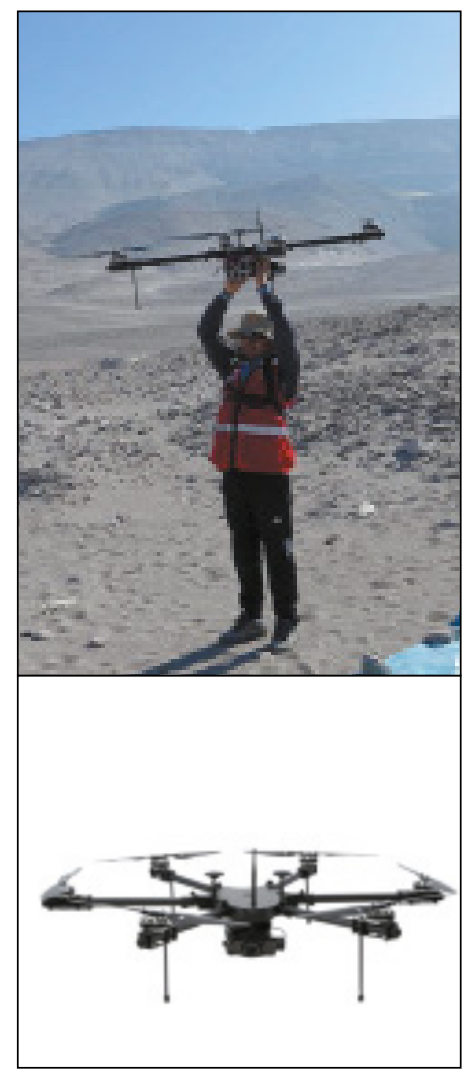

Figura 12. Equipo de vuelo Hexacóptero Abox 6, empleado durante las misiones de vuelo fotogramétricas, de fabricación peruana. (Robotic Air Systems). Repositorio fotográfico del Proyecto de investigación arqueológica Toro Muerto, 2019 coordenadas locales asociadas a las imágenes, obteniendo la más precisa datación para generar la reconstrucción 3D y su respectiva representación gráfica o renderización (ver Figura 11). Además, se realizaron pruebas haciendo uso de una Phantom 4 PRO comercial perteneciente al equipo de Arqueomática, de esta manera se obtuvo una serie de fotos a rocas con una volumetría mayor a 10 por 5 metros (de largo y ancho) por 2 de alto, siendo la Phantom, una herramienta de gran ayuda para este tipo de intervención.

El procesamiento de estos modelos se hizo con soportes de softwares computarizados como el Agisoft PhotoScan, de esta manera se obtienen resultados como la captura de imágenes térmicas o multiespectrales. El procesamiento de cada uno de estos modelos puede tener una duración de uno o dos días y el producto final de cada modelo puede llegar a tener un peso de $1 \mathrm{~GB}$ a $2 \mathrm{~GB}$ en formato MP3.

\section{Sobrevuelos con RPA}

Esta tarea correspondió al equipo del IGN, el cual, por lo exclusivo del trabajo se describirá líneas siguientes.

\section{Fotogrametría automatizada haciendo empleo del RPA aplicado al Sector "X"}

El perfeccionamiento de técnicas que permiten gestionar información de una porción del planeta, constituyen las herramientas ideales para aplicar metodologías fotogramétricas a la arqueología, las cuales se pueden convertir en mapas de alta resolución, hoy en día el empleo de RPA representa una importante herramienta para la captura de imágenes de alta resolución y temporalidad (Escalante, Cáceres \& Porras, 2016, pp. 120).

\section{Metodología}

El levantamiento fotogramétrico se realizó empleando una RPA. Dicho ejercicio consistió en tres etapas: Vuelos de reconocimiento, misiones de vuelo RPA y procesamiento en gabinete.

El equipo RPA empleado en la misión de vuelo fue un Hexacóptero ABOX 6, desarrollado - principalmente- para labores de topografía, cartografía, rescate, seguridad, y vigilancia. Diseñado y fabricado por la empresa peruana Robotic Air 


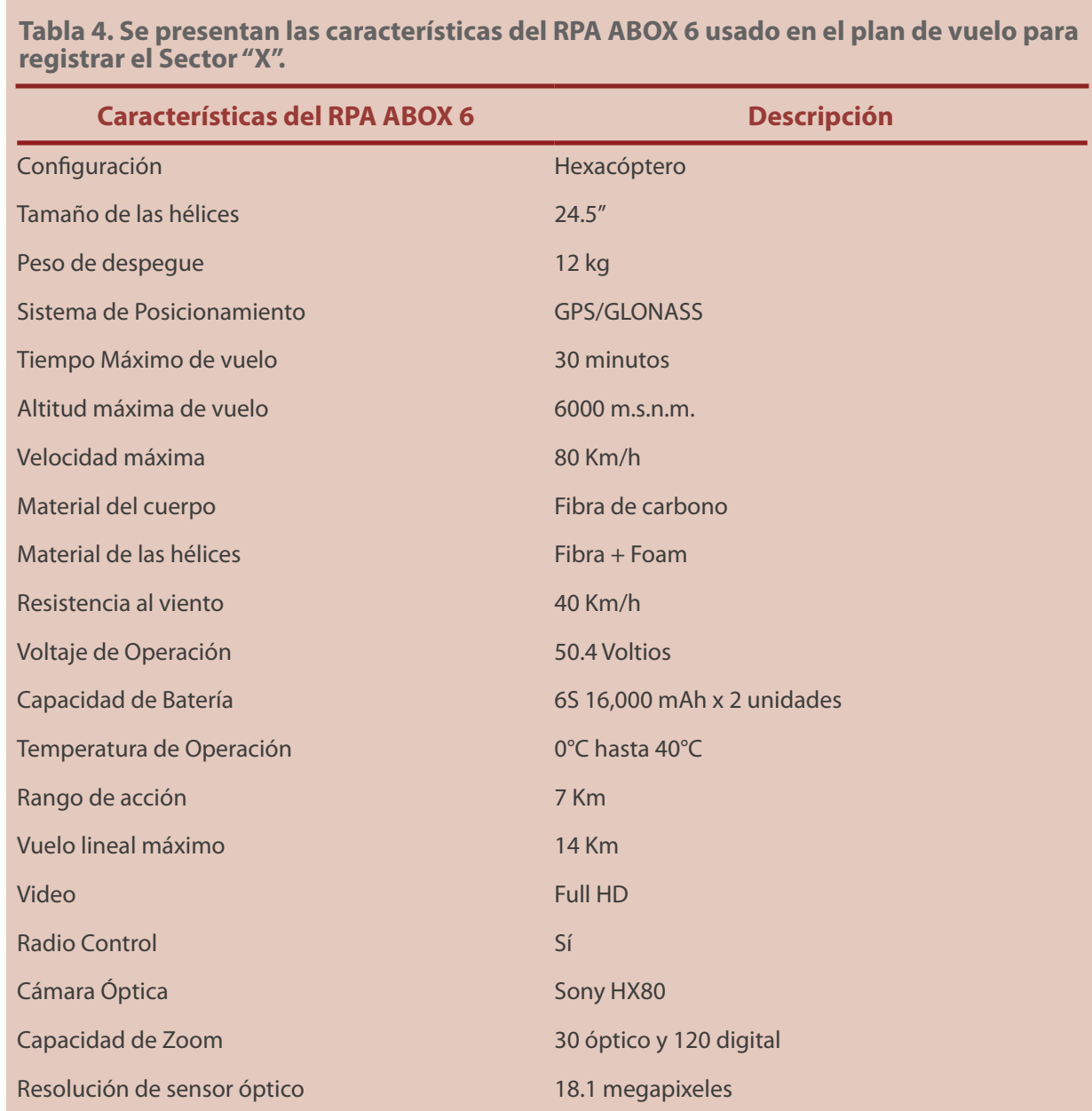

Elaboracion propia sobre la base de los datos obtenidos de http://www.roboticairsystems.com/abox6, 2019.

Systems ${ }^{17}$, y hasta el momento utilizado exitosamente en las distintas condiciones geográficas y agrestes del Perú, sobrepasando los 6000 m.s.n.m. Gracias a las intervenciones del IGN el RPA ABOX 6 ha sido puesto a prueba para el reconocimiento arqueológico en Toro Muerto (ver Figura 12 y Tabla 4), brindando grandes aportes para el registro. Su diseño ligero en fibra de carbono hace que logre tener una resistencia al viento de hasta $40 \mathrm{Km} / \mathrm{h}$, y tolerar temperaturas de $40^{\circ} \mathrm{C}$. El sistema de posicionamiento (GPS) incluido permitió que este equipo pueda viajar siguiendo la morfología del terreno.

\section{Vuelos de reconocimiento}

Parte del protocolo de vuelo es la seguridad, por ello, se procedió a realizar un reconocimiento a pie, por la zona de elevaciones que delimitan el polígono superior del área de mapeo (ver Figura 13), con la finalidad de verificar la altitud con el navegador personal. Una vez constatadas las alturas se pueden generar las misiones de vuelo con RPA, respetando el perfil de elevación. 
devenir Vol. 7, N¹3, ENERO- JUNIO 2020, PP. 77-102 - ESTUDIOS | ISSN 2312-7562 | E-ISSN 2616-4949

UNIVERSIDAD NACIONAL DE INGENIERÍA, LIMA

doi: https://doi.org/10.21754/devenir.v7i13.765

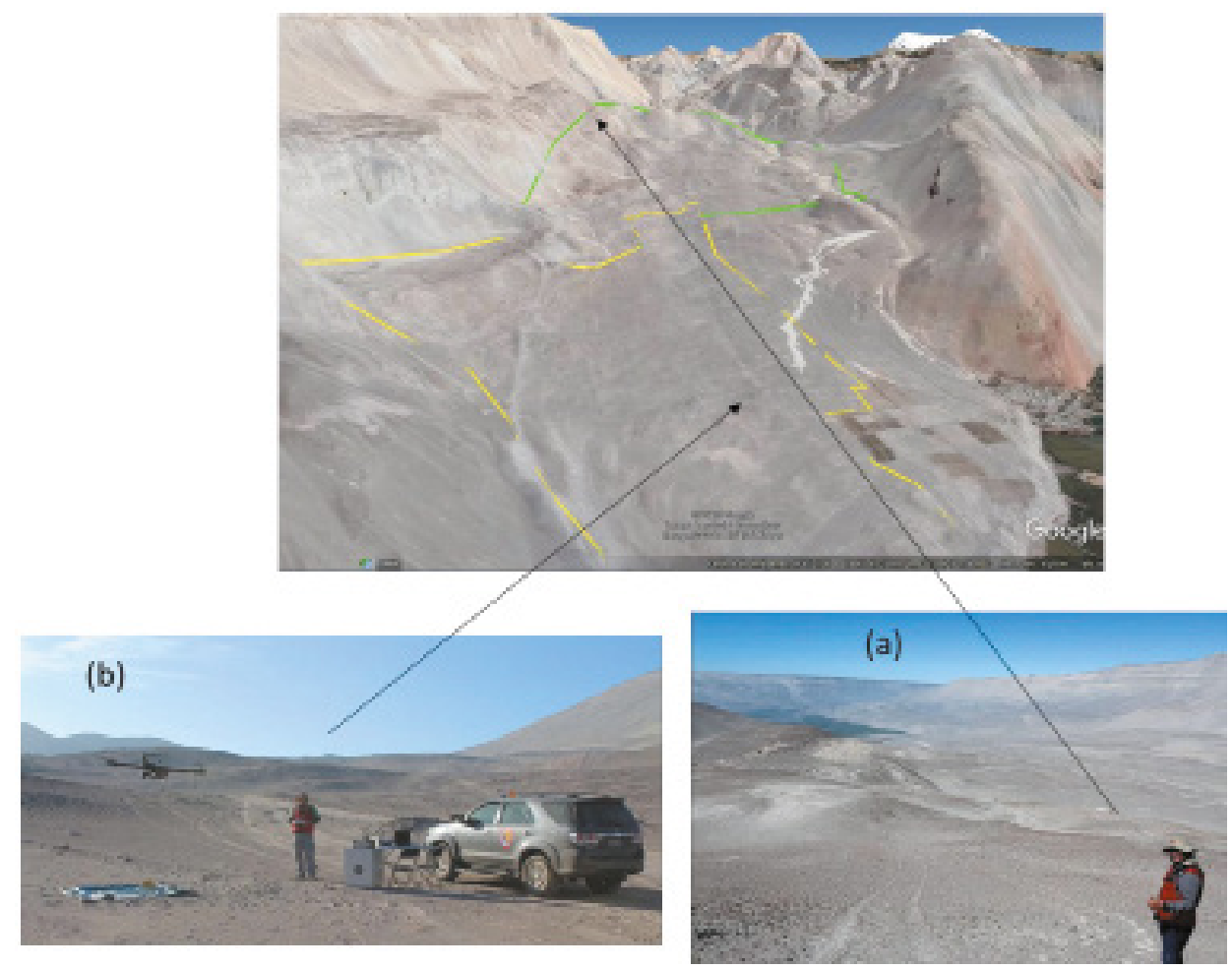

Figura 13. (a) Reconocimiento a pie para verificar alturas máximas antes de iniciar las misiones de vuelo fotogramétricas empleando RPA, (b) Vuelos de entrenamiento sobre la zona de interés. Archivo fotográfico del M.Sc. Fabian Brondi y fotografía de Google Earth, 2019.

\section{Misiones de vuelo RPA}

Reconocidas las altitudes del extremo norte (1200 a 1300 msnm), donde se halla el Sector "X" $y$ finalizados los vuelos de entrenamiento, se generaron las misiones de vuelo organizadas en polígonos para un adecuado solape entre sí, respetando la distribución espacial de cada uno (ver Figura 14), el Sector "X" se encuentra en el polígono B6 (ver Tabla 5).

Con los polígonos diseñados, se empleó una aplicación para crear planes de vuelo con el RPA, automatizados, conocido en el mercado como Mission Planner, el sofware descargado para las misiones de vuelo que se usaron para Toro Muerto es Ardupilot $^{18}$. La ventaja de esta metodología permite generar misiones respetando el perfil de elevación de la zona de interés y el traslape entre polígonos, de esta manera se mantiene un tamaño de pixel uniforme durante el procesamiento en gabinete. Esta aplicación es una estación de control en tierra para ordenadores, compatible sólo con Windows.

Las misiones de vuelo fueron 11 en total, y tuvieron características resaltantes como haber logrado generar aproximadamente 120 disparos fotográficos por polígono y obtener una ortofoto de $6 \mathrm{~cm}$ por pixel.

Debido a la distribución de los polígonos de vuelo sobre la zona de trabajo, especialmente la del Sector " $X$ ", fue necesario desplazar la estación móvil de fotogrametría con el objetivo de completar el mapeo poligonal de manera sostenida, teniendo 

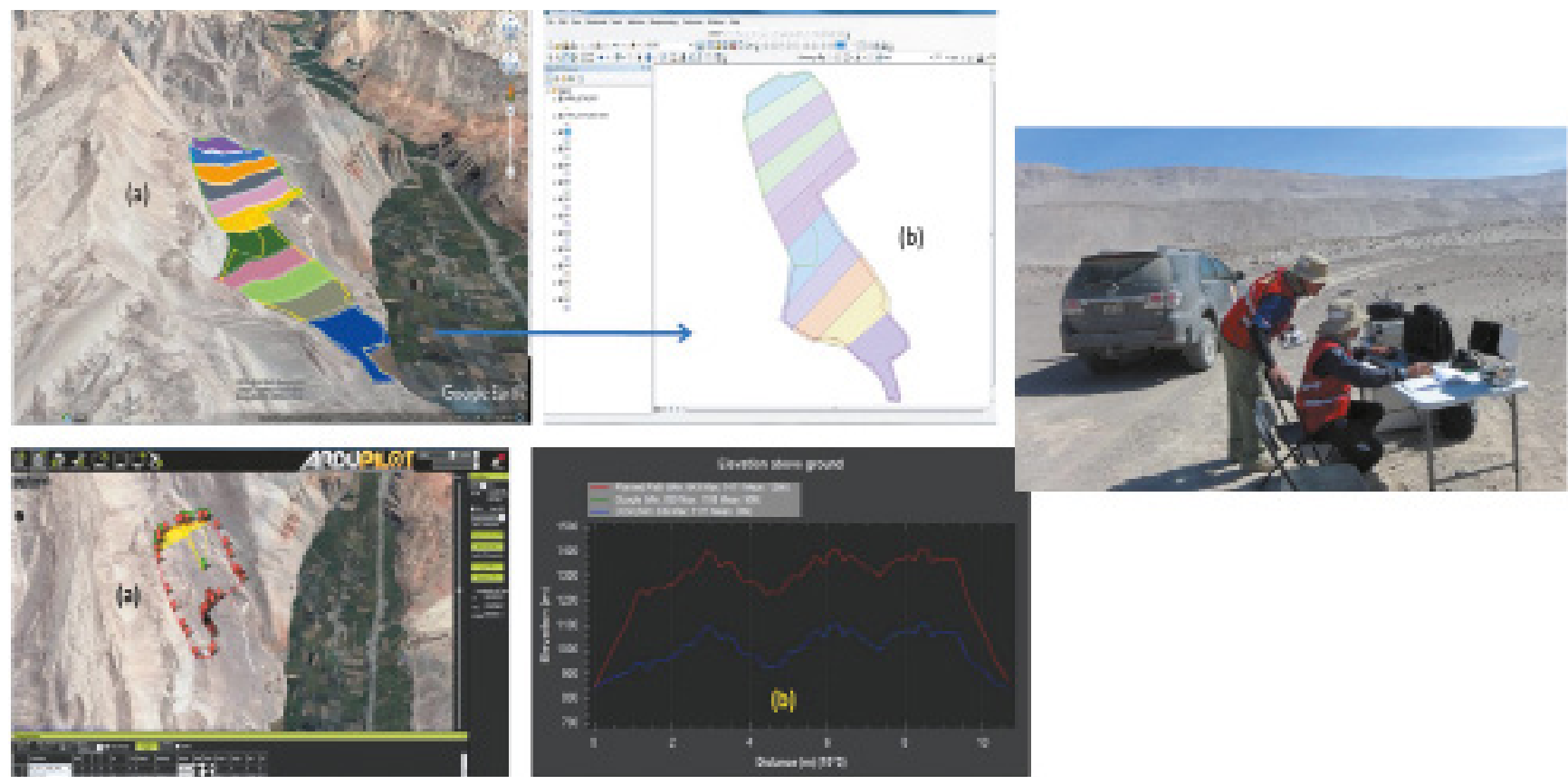

Figura 14. (a-b superior) Generación de misiones de vuelo poligonales en formato KMZ y conversión de polígonos al formato SHP. (a-b inferior) Vista de la interfaz del programa Mission Planner y verificación del perfil de elevación de la zona de vuelo (la línea de color rojo representa el desplazamiento del RPA en relación al terreno). Imágenes elaboradas por el M.Sc. Fabian Brondi en base al repositorio fotográfico del Proyecto de investigación arqueológica Toro Muerto, 2019.

Tabla 5. Detalle de las 11 misiones de vuelo ejecutas sobre la zona de interés.

\begin{tabular}{cc}
\hline Características & Descripción \\
\hline Cantidad de polígonos & 11 \\
Productos & Ortofoto/DSM \\
Equipo & ABOX 6 \\
Altura (mts) & 200 \\
(\%) Solape Vertical & 60 \\
(\%) Solape Horizontal & 80 \\
Vuelo (mts/sg) & 10 \\
Resolución cm x pix & 6 \\
No fotos polígono & 120 (aprox) \\
Área (ha) por polígono & $100-120$ \\
Tiempo de vuelo (min) & 31 \\
\hline
\end{tabular}

Elaboración propia en base a la data del Proyecto de investigación arqueológica Toro Muerto, 2019. 
devenir Vol. 7, N¹3, ENERO- JUNIO 2020, PP. 77-102 - ESTUDIOS | ISSN 2312-7562 | E-ISSN 2616-4949

UNIVERSIDAD NACIONAL DE INGENIERÍA, LIMA

doi: https://doi.org/10.21754/devenir.v7i13.765

Figura 15. (a) Tabla con las características de la ortofoto y modelo digital de terreno (b) Ortofoto de la zona de trabajo, (c) Modelo digital de terreno de la zona de trabajo con rampa de color, representando los valores altitudinales. Repositorio fotográfico del Proyecto de investigación arqueológica Toro Muerto, 2019.

Figura 16. Mapa temático donde se consigna la distribución espacial de los petroglifos correspondiente al área de estudio, escala 1: 1000. Esquemas elaborados por el M.Sc. Fabian Brondi y el Tco. Geo. Elías Apaico para el Proyecto de investigación arqueológica Toro Muerto, 2019.
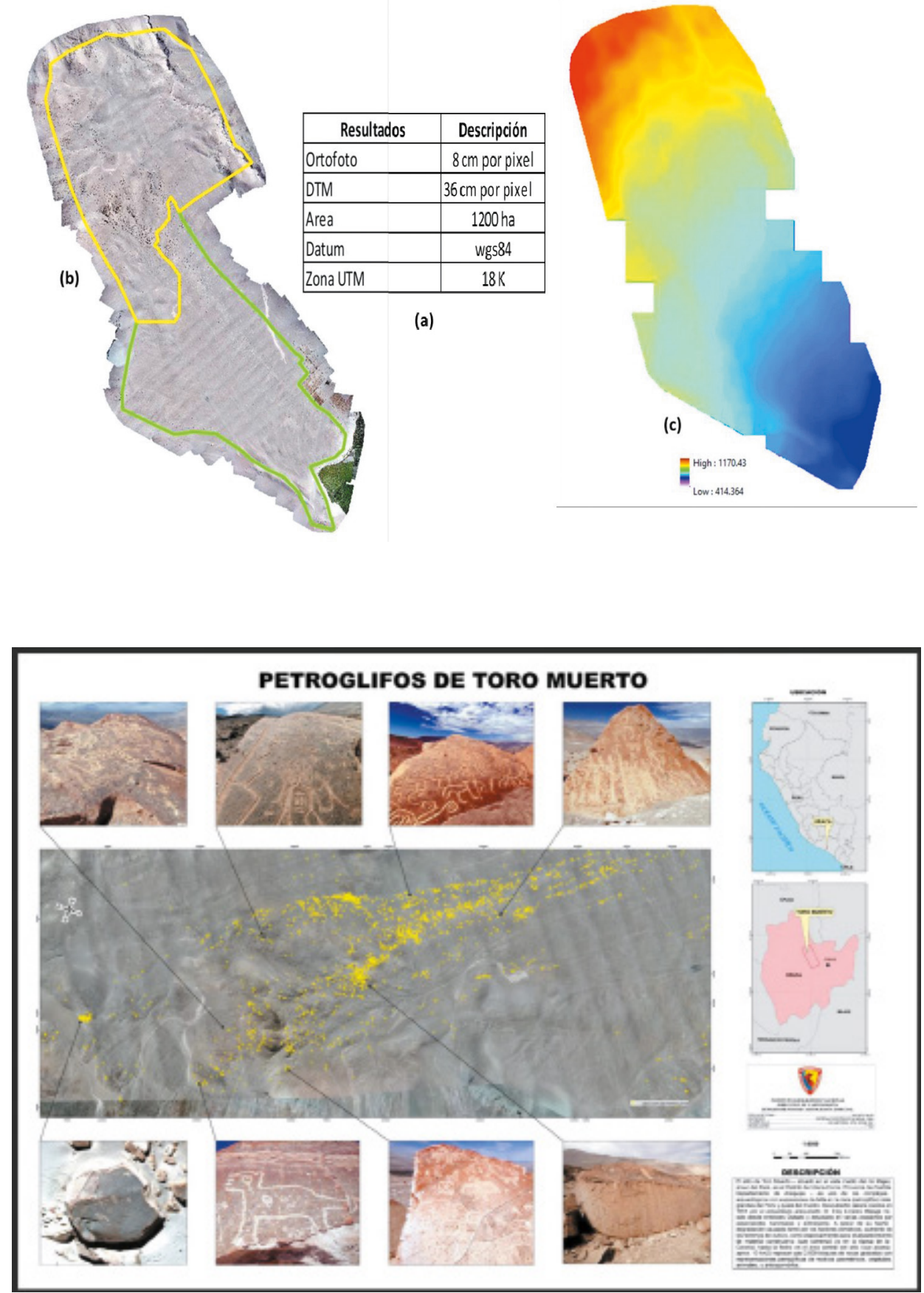

en consideración el cambio de las condiciones del tiempo, ya que, a partir de las 14:00 horas, la velocidad del viento superaba los $40 \mathrm{~km} / \mathrm{h}$. En paralelo al trabajo fotogramétrico, se contó con el equipo geodésico (GPS-RTK) del PIA-TM y operado por el equipo de Arqueomática, se establecieron 7 puntos de control en todo el sitio, de los cuales uno destaca para el Sector "X", de esta manera se llevó a cabo el ajuste respectivo. 


\section{Procesamiento en gabinete}

Finalizadas las misiones de vuelo y su posterior verificación en campo, se procesaron las fotografías empleando el programa fotogramétrico para imágenes RPA Pix $4 d^{19}$, el cual está ajustado para procesar un conjunto de fotos y calibrarlas por medio de algoritmos de visión computarizadas, de esta manera se puede obtener imágenes térmicas y multiespectrales en mapas 3D y modelo 3D (ver Figura 15). Los puntos de control geodésicos ayudaron en el ajuste de precisión. Finalmente, como productos obtenidos para el Sector " $X$ ": Ortofoto, Modelos Digitales de Elevación, modelos en tres dimensiones y mapa temático escala 1:1000 (ver Figura 16).

\section{Resultados}

Es de manifestar, que después de 5 temporadas de trabajo (campo y gabinete) por parte de la delegación polaco-peruana (PIA-TM y PTM) se ha logrado obtener la primera y más precisa documentación de los petroglifos de Toro Muerto, en total 2584 rocas (en un área de 10km2), y de los cuales se deben sumar aún una serie de rocas aisladas, llegando a contabilizar, de seguro, un aproximado de 2600 rocas con petroglifos, sin embargo, las 2584 registradas hasta hoy, cuentan con:

1. Inventario General

2. Documentación descriptiva (fichas)

3. Documentación fotográfica detallada

A esta documentación base se ha sumado algunos trabajos como los de

4. 300 calcos entre tradicionales y electrónicos, y

5. 50 modelos 3D de una serie de rocas seleccionadas.

Sin embargo, especialmente, como se ha descrito, el Sector " $X$ ", que cuenta con 92 rocas con manifestaciones rupestres, desde el $\mathrm{N}^{\circ} 2470$ al $\mathrm{N}^{\circ} 2561$ las que han sido documentadas y georreferenciadas bajo los procesos metodológicos detallados anteriormente. Por consiguiente, respecto a la fotogrametría automatizada se puede concluir que:

6. Las técnicas de edición de fotografías digitales permiten ecualizar la tonalidad de una imagen, de esta manera se pueden apreciar detalles que por efectos del exceso de iluminación pueden pasar desapercibidos (ver Figura 17).

7. Es posible digitalizar las imágenes de los petroglifos a través de un entorno GIS e incluso desde el Google Earth, cuando el producto final ha sido transferido al formato KMZ (ver Figura 18)

8. La construcción del modelo 3D del terreno permite analizar no sólo la iconografía en los paneles, sino, incluso, se obtiene una mejor idea del tránsito y visualización del sector respecto al entorno paisajístico (ver Figura 19)

\section{Virtualización del Patrimonio Cultural Rupestre y la gestión interinstitucional}

Urge proponer métodos para la virtualización del patrimonio cultural rupestre peruano, en vista que en las últimas décadas se ha observado un gran deterioro no sólo en las rocas mismas, sino, en su entorno paisajístico inmediato, ya sea a causa de la 
devenir Vol. 7, N¹3, ENERO - JUNIO 2020, PP. 77-102 - EstudIOS | ISSN 2312-7562 | E-ISSN 2616-4949

UNIVERSIDAD NACIONAL DE INGENIERÍA, LIMA

doi: https://doi.org/10.21754/devenir.v7i13.765

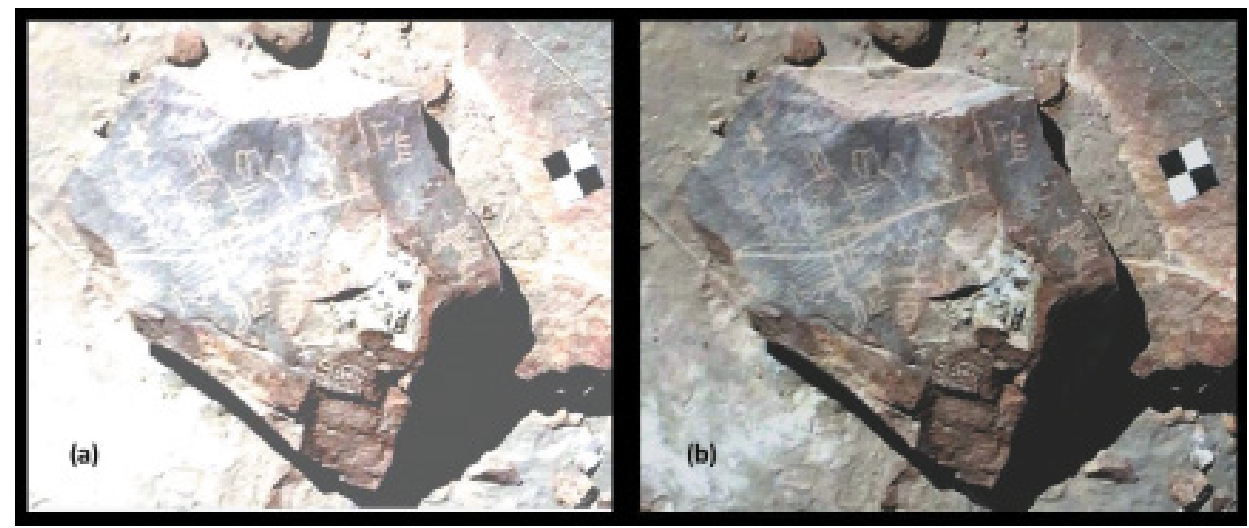

Figura 17. (a) Imagen de petroglifo con exceso de iluminación, (b) Misma imagen ecualizada. Esquema elaborado por el M.Sc Fabian Brondi en base al repositorio fotográfico del Proyecto de investigación arqueológica Toro Muerto, 2019.

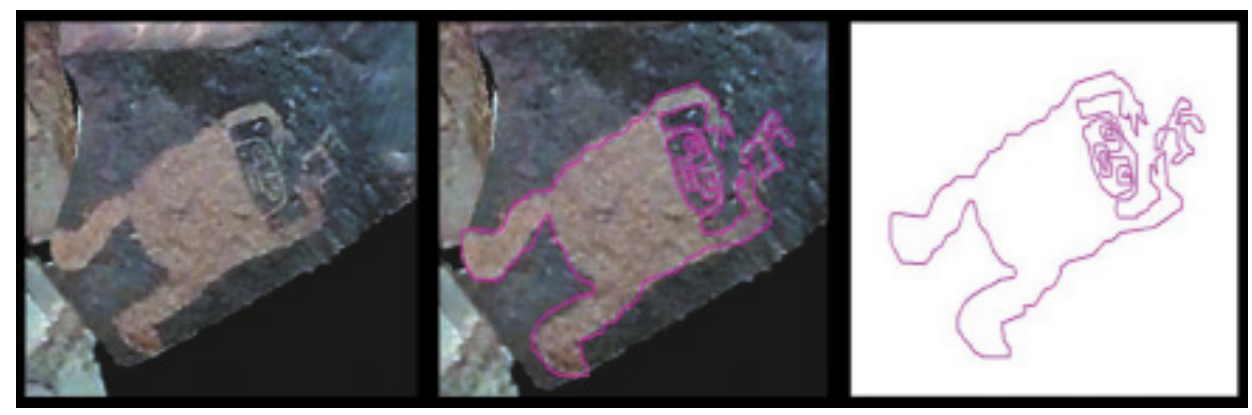

Figura 18. Etapas de digitalización de una imagen de interés. Esquema elaborado por el M.Sc Fabian Brondi en base al repositorio fotográfico del Proyecto de investigación arqueológica Toro Muerto, 2019.

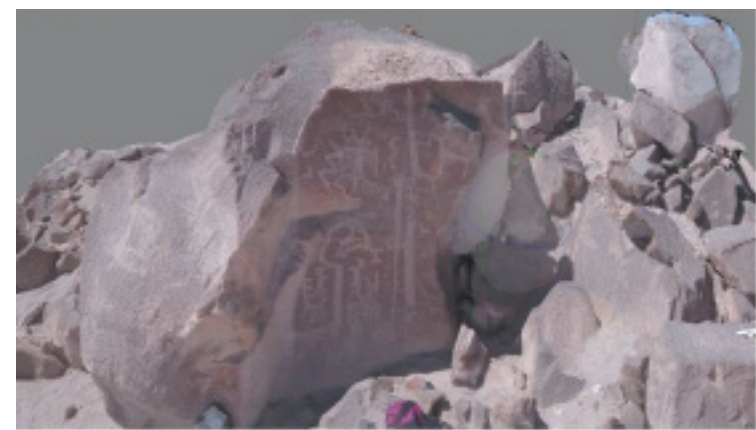

(a)

(b)

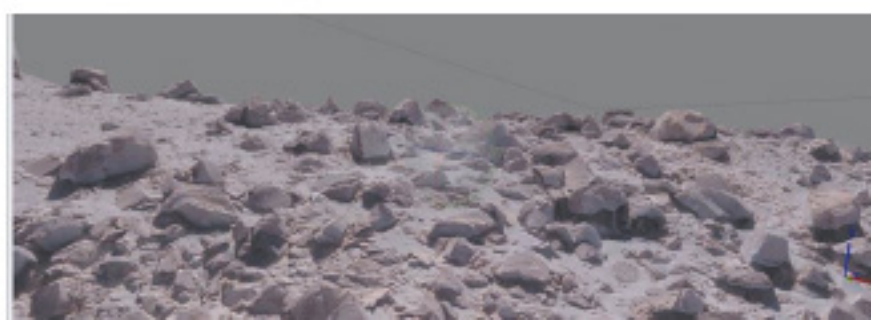

Figura 19. (a) Vista de un petroglifo construido en tres dimensiones, en donde se puede apreciar el detalle de las imágenes laterales (b) Vista panorámica en tres dimensiones de un agrupamiento de petroglifos. Esquema elaborado por el M.Sc Fabian Brondi en base al repositorio fotográfico del Proyecto de investigación arqueológica Toro Muerto, 2019. 
minería, la agroindustria, el crecimiento urbano o la carga turística. Ya no se puede justificar la falta de equipos y/o insumos tecnológicos en el mercado (de fácil acceso y bajo costo) para virtualizar el patrimonio cultural rupestre, principalmente si este se encuentra en peligro, y a ello se debe sumar la gestión interinstitucional, que de ser bien llevada puede resolver una primera etapa: registro e inventario.

Siguiendo las consideraciones de la Carta de Londres, y en cumplimiento con todas las reglamentaciones de las instituciones peruanas que velan y protegen el patrimonio cultural, el equipo del PIA-TM realiza dichas intervenciones (en lo ya expuesto), donde una parte de los recursos tecnológicos con los cuales se ha contado para realizar los productos finales de virtualización del patrimonio cultural rupestre de Toro Muerto, especialmente el Sector " $\mathrm{X}$ ", han sido planteados en base a los conceptos que se maneja sobre la Tecnología Apropiada, tipo de actividad que tiene entre su principal discurso el uso de tecnología de procedencia local y el aprovechamiento de programas (softwares) de fácil manejo y bajo costo, e inclusive, gratuitos. Lo que se desea manifestar es la posibilidad de ampliar el capital económico haciendo uso de herramientas útiles, gestionando el apoyo de una serie de intervenciones de instituciones científicas para beneficio del patrimonio y obteniendo resultados objetivables y fiables.

\section{Conclusiones}

El empleo de tecnología RPA, fusionado con las técnicas geomáticas (Sistemas de información geográfico, geodesia, teledetección, entre otros), permiten generar información geoespacial de altísima resolución y adecuada temporalidad, sumamente necesaria para una serie de investigaciones asociadas al patrimonio cultural, de esta manera la información se puede evaluar a través de una óptica consensuada y a la vez objetiva.

A pesar de que el trabajo expuesto no manifiesta ningún tipo de particularidad sobre patrimonio edificado histórico, se puede justificar que gracias a los aportes y a la elaboración detallada de los modelos $3 \mathrm{D}$ del terreno y el registro minucioso de cada petroglifo (sumado a las excavaciones in situ) se podrá analizar por medio del SIG lo siguiente:

1. El manejo territorial manifestado en los diferentes procesos culturales y de apropiación cultural del terreno a lo largo de más de un milenio (100 a.c al 1400 d.c.), y obtener un mapeo cronológico.

2. Se logrará sectorizar el terreno, siguiendo una serie de rasgos espaciales y tipologías iconográficas, de esta forma se entenderá el porqué de la ubicación casi aislada del Sector "X".

3. La creación de algoritmos específicos para el reconocimiento de la iconografía, que sustente las diferenciaciones entre las imágenes del Sector Central y el Sector "X".

4. Antecedente de registro ante posibles destrucciones, especialmente la agroindustria y crecimiento urbano. En el caso del Sector " $\mathrm{X}$ " ante la posible habilitación turística en el sector.

5. Monitorear con mayor claridad el deterioro por parte del efecto natural y/o antrópico.

6. A esta base de datos se podrá integrar con facilidad tres aspectos importantes de los estudios del paisaje cultural: circulación, visualización y acústica.

En conclusión, queda claro que el trabajo de virtualización obtenido en el Sector " $\mathrm{X}$ " (y en general en Toro Muerto) es el primer paso para analizar el manejo territorial y espacial del sitio, a ello, se debe resaltar que es el primer trabajo de virtualización del patrimonio cultural rupestre realizado no sólo en la Región de Arequipa, sino, en el Perú. El equipo 
devenir Vol. 7, N¹3, ENERO- JUNIO 2020, PP. 77-102 - ESTUDIOS | ISSN 2312-7562 | E-ISSN 2616-4949

UNIVERSIDAD NACIONAL DE INGENIERÍA, LIMA

doi: https://doi.org/10.21754/devenir.v7i13.765

profesional del PIA-TM espera que este trabajo sea reconocido como método para la aplicación del registro-documentación-virtualización de sitios con arte rupestre a cielo abierto en el Perú, ya que una serie de sitios a lo largo de la costa peruana presentan las mismas características espaciales.

\section{Agradecimientos}

Se agradece a todos los miembros del PIA-TM participantes de las Temporadas 20172018, al Dr. Andrzej Rozwadowski (Universidad. Adam Mickiewicz de Poznań, Polonia), Aleksandra Lisek, Beata Jurkiewicz, Miguel Macedo Rojas, Emily Ramírez Anaya, Amparo Chávez, Lesly Tapia Rubina. A los voluntarios peruanos: Becker Ascona, Manuel Morón y Néstor Lagos. A los voluntarios extranjeros, Mónica Ayala (Chile), Viridiana Hernández (México) y Fabian Simeon (Suiza).

Se agradece, además, al Instituto Geográfico Nacional del Perú, por permitir la participación de los especialistas en geomática incluyendo al Tec. Alexis Camargo. A la empresa peruana Robotic Air Systems por permitir operar el RPA ABOX 6, de su entera fabricación y propiedad.

Asimismo, a los encargados de la Dirección General del Patrimonio Arqueológico del Ministerio de Cultura del Perú, por emitir los permisos correspondientes para la ejecución del PIA-TM. A Marko López Hurtado, quien supervisa las labores de campo y gabinete como representante de la Dirección Desconcentrada de Cultura de Arequipa.

Finalmente, a los investigadores Willy Yépez, Rainer Hostnig y José Vargas por los conocimientos prestados y al Sr. Ramón Zegarra Prado, exalcalde del distrito de Uraca por el apoyo al PIA-TM.

\section{Referencias}

Barreda, J. , Granado, G., \& Aguilar, J. (2017). Aplicación de la fotografía métrica en edificación mediante el uso de la cámara digital convencional: un caso de estudio aplicado al patrimonio arqueológico. Anales de Edificación, 3 (1), 1-13.

Bednarik, R. (1991). The IFRAO Standard Scale. Rock Art Research (8), 78-79.

Bernedo, L. (01 de enero de 1936). Las ruinas de Pujchun, en Chuquibamba, empino de símbolos de la civilización preincaica. El Deber, 4-5.

Bingham, H. (1912). The Ascent of Coropuna. (H. M. Alden, Ed.) Harper's New Monthly Magazine, 125 (741-45), 489-502.

Criado-Boado, F. (2018). Arqueológias del Espacio: Aproximación a los modos de existencia de los xscapes. En L. Flores Blanco (Ed.), Lugares, Monumentos, Ancestros: Arqueologías de paisajes andinos y lejanos (pp. 25-52). Lima, Perú: Auqui Ediciones.

Escalante, J. O., Cáceres, J., \& Porras, H. (diciembre de 2016). Ortomosaicos y modelos digitales de elevación generados a partir de imágenes tomadas con sistemas UAV. Tecnura, 20 (50), 119-140. doi: http://dx.doi.org/10.14483/udistrital.jour.tecnura.2016.4.a09

Fiore, D. (2018). The Materiality of Rock Art: Image-making technology and economy viewed fron Patagonia. En A. Troncoso, F. Armstrong, \& G. Nash (Edits.), Archaeologies of Rock Art: South America Perspectives (pp. 23-57). New York: Routledge.

Fux, P., Sauerbier, M., Kersten, T., Lindstaedt, M., \& Eisenbeiss, H. (2-6 de Abril de 2009). Documentation and Interpretation of the Petroglyphs of Chichictara, Palpa (Peru), Using Terrestrial Laser Scanning and Image-Based 3D Modeling. Layers of Perception. Proceedings of the 35th International Conference on Computer Applications and Quantitative Methods in Archaeology (CAA), 10, pp. 65-71. Berlin.

Fux, P., Sauerbier, M., Kersten, T., Lindstaedt, M., \& Eisenbeiss, H. (2009). Perspectives and Contrasts: Documentation and Interpretation of the Petroglyphs of Chichictara, Using 
Terrestrial Laser Scanning and Image-Based 3D Modeling. Natural Science in Archaeology, 359-377.

Gonzales, L. (2018). Informe Final del Proyecto de Investigación Arqueológica sin excavaciones en el sitio con Arte Rupestre de Toro Muerto - Arequipa. Lima.

Jennings, J., van Hoek, M., Yépez Álvarez, W., Bautista, S., San Miguel Fernández, R., \& Spence-Morrow, G. (2019). Illonas: The three thousand year history of a rock art site in Southern Peru. Ñawpa Pacha, 1-31. doi:10.1080/00776297.2019.1635313

Juszczyk, K., Woloszyn, J., \& Rozwadowski, A. (2018). Documentando Toro Muerto (Arequipa-Perú): Informe de las temporadas 2015-2017. Boletín SIARB (32), 36-42.

Kroeber, A. (1944). Peruvian Archaeology. New York: Viking Fund.

Linares, E. (2011). Memorias del Arqueologo Eloy Linares Málaga: 80 años de edad y 60 de Investigador. Lima: Universidad Alas Peruanas.

Linares, E. (2014). Cómo inventariar arte rupestre en los Andes Meridionales. Boletín Oficial APAR, 05 (19-20), 831-879. Recuperado el 25 de setiembre de 2019, de https://issuu.com/ apar/docs/boletinapar5_19_20

Mendoza, J. (2010). Petroglifo de las Calderas. Boletín de Lima (162), pp. 15-16.

Morante, J. (1949). Arqueología de Arequipa. Revista Universitaria (01).

Núñez, A. (1986). El libro de piedra de Toro Muerto. La Habana.

Núñez, A. (1986). Petroglifos del Perú. Panorama mundial del arte rupestre. La Habana, Cuba.

Paz de Novoa , C. (1940). Paigchana, su cementerio, y sus petroglifos. Actas y trabajos científicos del XXVII Congreso Internacional de Americanistas, Tomo I (pp. 531-544). Lima: Imprenta Gil S.A.

Pozzi-Escot, M. (2009). Los petrogifos de Toro Muerto (Valle de Majes, Arequipa - Perú, inventario y registro. En M. Sepúlveda, L. Briones , \& J. Chacama (Ed.), Crónicas sobre la piedra: Arte Rupestre de las Américas. VII Simposio Internacional de Arte Rupestre (pp. 49-361). Arica: Universidad de Tarapacá.

Quesada, E. (2008). Aplicación Dstretch del softwarelmage-J. Avance de resultados en el ArteRupestre de la Región de Murcia. Cuadernos de Arte Rupestre (5), pp. 14-47.

Quinto, S. (2016). Uso y Aprovechamiento de las nuevas tecnologías en la conservación del patrimonio edificado: Reseña de casos emblemáticos en Perú. Devenir, pp. 113-132.

Ravines, R. (2016). Toquepala: Arqueología. Boletín de Lima (182), 356.

Rosińska, D., \& Díaz, L. (2008). Diversidad arqueológica en Toro Muerto, sur del Perú. Tambo. Boletín de arqueología (I), pp. 83-98.

Rosińska, D., \& Díaz, L. (2016). Valle de Majes: un paisaje simbólico. Tambo. Boletín de arqueología (III), pp. 355-389.

Seoane-Veiga, Y., Santos, M., \& Troncoso, A. (2009). Metodología para el relevamiento de Arte Rupestre a partir de calcos sobre plástico: Aplicación a petroglifos de la cuenca superior del río Aconcagua, Chile Central. En L. B. M. Sepúlveda (Ed.), VII Simposio Internacional de Arte Rupestre. Capítulo 2: Teoría de la metodología de la investigación (pp. 141-152). Arica: Universidad de Tarapacá.

Troncoso, A., Armstrong, F., \& Nash, G. (2018). Contemporary approaches to rock art in South America: Introductory remarks. En A. Troncoso, F. Armstrong, \& G. Nash (Edits.), Archaeologies of Rock Art: South America Perspectives (pág. 301). New York: Routledge.

Umire, A. (2015). Los "listados": petroglifos del Alto de la Caldera en Arequipa, sur de Perú. Recuperado el 01 de octubre de 2019, de http://www.rupestreweb.info/lacaldera.html

van Hoek, M. (2005). Toro Muerto, Peru Possible Prehistoric Deletion of Petroglyph. Recuperado el 25 de setiembre de 2019, de http://www.rockartscandinavia.com/images/articles/ a05hoek.pdf 
devenir Vol. 7, N¹3, ENERO - JUNIO 2020, PP. 77-102 - EstudIOS | ISSN 2312-7562 | E-ISSN 2616-4949

UNIVERSIDAD NACIONAL DE INGENIERÍA, LIMA

doi: https://doi.org/10.21754/devenir.v7i13.765

van Hoek, M. (2005). Toro Muerto, Perú. Posibles alteraciones prehistóricas en detalles de petroglifos. Recuperado el 25 de setiembre de 2019, de http://www.rupestreweb.info/ toromuerto.html

van Hoek, M. (2010). Trophy Heads in the Rock Art of the MajesValley, Perú: Exploring their Possible Origin. Rupestreweb. Recuperado el 26 de setiembre de 2019, de http://www. rupestreweb.info/trophy.html

van Hoek, M. (2013). The Carcancha and the Apu. Rock Art in the Death Valley of the Andes. Recuperado el 25 de setiembre de 2019, de http://www.rupestreweb.info/carcancha.html

van Hoek, M. (2018). Formative Period Rock Art in Arequipa Peru: An Updated Analysis of the Rock Art from Caravelí to Vítor . Oisterwijk.

Vargas Oblitas, J. M. (12 de marzo de 2015). Melgar, Corire y el Valle de Majes. Uraca-Corire, Castilla-Arequipa, Perú: Municipalidad Distrital de Uraca-Corire.

Wołoszyn, J., Gonzales Ruiz, L. M., \& Rozwadowski, A. (diciembre de 2019). The petroglyphs of Toro Muerto: new documentation and discoveries at the largest South American rock art complex. Antiquity. 